Implicaciones económico-territoriales del auge exportador mexicano

\title{
Guillermo Olivera*
}

En la primera parte de este trabajo se analiza el comportamiento de las expor. taciones manufactureras en México desde la década de los ochenta hasta mediados de los noventa, como resultado de la crisis económica y de los programas de ajuste internos, en el contexto de la reestructuración de la economía mundial originada en los paises industrializados durante los años setenta. En una segunda parte se muestran los cambios en la geografía industrial que resultan de lo anterior, para lo cual se distinguen las ramas de actividad que comandan las exportaciones manufactureras y se determina su peso en el empleo y en el PIB sectorial. Finalmente, se incluyen algunas recomendaciones de politica industrial en función del dinamismo y localización de las distintas ramas manufactureras según su diferente condición exportadora.

\section{Vínculos economía-territorio}

Como resultado de la recesión económica que al inicio de los años setenta experimentó la mayoría de los países del primer mundo, el espacio económico inició una nueva ampliación, y con ella se descentralizó el mercado de bienes y servicios. Por esta razón, a los tradicionales asuntos de interés de la economía (qué y cómo producir) se agregó otro aspecto de igual importancia para poder cumplir con los estándares que exigía la competencia internacional: la cuestión de dónde producir. Si bien ello nunca ha dejado de considerarse, la posibilidad tecnológica de fragmentar los procesos productivos y reducir las distancias para disminuir los costos, acentuó la pertinencia de su inclusión en las decisiones estratégicas de las empresas.

El territorio deja de percibirse como un elemento estructurado por la economía para ser considerado un factor estructurante, en el entendido de que las ventajas o desventajas que éste representa para competir en la economía mundial están determinadas socialmente. Es decir, la posibilidad de potenciar o anular las condiciones de ubicación geográfica y la disponibilidad de recursos naturales de los países están dadas por las características de su población, su base económica, relos.

* Centro Regional de Investigaciones Multidisciplinarias, UNAM, Cuernavaca, Mo- 
el grado de desarrollo tecnológico alcanzado, la gestión económicoadministrativa de los distintos niveles de gobierno, las estrategias de inversión de las corporaciones trasnacionales, el marco jurídico y orden institucional, los atributos del empresariado local, y los rasgos físicos del territorio. Este conjunto de factores internos, externos, estructurales y de coyuntura se traduce en una determinada capacidad de las empresas nacionales para articularse, favorable o desfavorablemente, en las redes productivas globales, y se concreta en la desigual participación de los países en los flujos internacionales de inversión y de comercio; con ello se configura un cambiante mapa económico mundial, y en el interior de cada nación se modifica la organización regional de la producción ${ }^{1}$-en el caso mexicano anteriormente funcional al mercado interno y ahora al mercado externo.

El origen de la reconfiguración territorial se encuentra en la reestructuración económica mundial, en la base de la cual a su vez está el agotamiento de las condiciones económicas, tecnológicas y sociales que hicieron posible el rápido crecimiento económico de la posguerra y la crisis estructural global de la rentabilidad y de la regulación (Dabat y Rivera, 1994: 6). En la complejidad del cambio desatado destacan el cambio de modelo económico dominante y el advenimiento de notables avances tecnológicos (o "tercera revolución industrial"). Lo primero se concretó en la pérdida de respaldo internacional a las prácticas del Estado de bienestar y a los instrumentos tradicionales (fiscales, crediticios y cambíarios) de apoyo al crecimiento económico, así como en la presión por favorecer el imperio del mercado y fortalecer la capacidad competitiva de las empresas.

En el aspecto tecnológico y de organización industrial, llegó a su límite el modelo de producción en serie o fordista, debido a su rigidez para responder a las nuevas condiciones de mercados fragmentados, a su dependencia de economías de aglomeración (concentración urbana) y de escala (predominio de la gran industria), y al alto costo que le representaban las conquistas laborales de años anteriores; todo ello le restaba competitividad a las grandes empresas en un

${ }^{1}$ Análisis detallados sobre los procesos de industrialización, desindustrialización y terciarización de las economías de algunos países industrializados en los años sesenta, setenta y ochenta pueden encontrarse en los trabajos de los siguientes autores: Massey (1986), y Dunford y Perrons (1986) para el caso de Gran Bretaña; Savey (1983) para Francia; Kontuly (1992) para Alemania; Dematteis (1986), y Cappecchi (1989) para ltalia; Smith y Feagin (1987), Frey (1989), Frey y Speare (1992), y Glickman (1987) para el caso de Estados Unidos. 
mercado mundial cada vez más diferenciado (véase De la Grarza, 1993).

Las nuevas tecnologías (informática, microelectrónica y biotecnología) y los recientes métodos organizacionales vinieron a terminar con la rigidez mencionada, a facilitar la producción en pequeños lotes en el momento exacto y a reducir el capital fijo, con lo cual se han favorecido la desconcentración territorial de la producción y la descentralización técnica (disminución del tamaño medio de las firmas). Esto ha contribuido a lograr mejoras en la calidad y diseño de los productos, así como a la reducción de la etapa de circulación (véase Lipietz y Leborgne, 1990).

El efecto de la reestructuración económica en los países del primer mundo y la revaloración del territorio (nuevos factores de localización) fue, principalmente, una notable redistribución de las actividades industriales entre estas naciones y los países de industrialización tardía de Asia y América Latina. El dinamismo industrial mostrado por ellos durante los últimos lustros en ciertas ramas es la contraparte del proceso de desindustrialización ${ }^{2}$ que se ha presentado en el primer mundo durante el mismo tiempo y en las mismas ramas.

En el caso de México, algunos estudios recientes muestran que los resultados de los factores externos e internos ya mencionados, $y$ sobre todo de la apertura económica de mediados de los años ochenta y el decidido impulso a las exportaciones manufactureras, fueron la acentuación de una estructura industrial heterogénea, una inevitable reestructuración urbana, y la reconfiguración de la geografía de la producción. En términos de estructura se desarrolla un sector ma-

${ }^{2}$ Datos de la Organización Industrial del Trabajo (OIT) muestran con claridad la pérdida de empleos en el sector industrial (desindustrialización) de los países del primer mundo o Grupo de los Siete. De hecho, en los dos últimos decenios se abrió en ellos un poco más de la mitad de las plazas que crearon el grupo de países de industrialización reciente (NIC's) y otros. En términos más precisos, el Grupo de los Siete tenía en 1991 dos millones trescientos sesenta y tres mil empleos manufactureros menos que en 1971, mientras que en el grupo de los NiC's y otros se crearon casi 20 millones de plazas. Las pérdidas para los primeros se concentraron en Reino Unido (2.7 millones), Italia (0.7), Francia (1.1) y Alemania (0.8) con un total de 5.4 millones; en tanto que los aumentos de 1.6 millones en Estados Unidos, 1.2 en la antigua Alemania Federal y 0.2 en Japón no compensaron las pérdidas. Las ganancias para el grupo de los NIC's y otros se repartieron entre Corea del Sur (3.5 millones), Indonesia (2.9), Tailandia (1.8), Ex Yugoslavia (1.1), India (1.1), Brasil (6.3), Filipinas (0.7), Turquía (0.7), México (0.6) y Venezuela (0.5) con un total de 19.5 millones (véase Guadarrama, 1995). 
nufacturero profundamente desarticulado en el cual pocas ramas y empresas industriales resultan beneficiadas (véase Dussel, 1995); las ramas de mayor contenido tecnológico, que coinciden en gran parte con las que han mostrado mayor dinamismo exportador, son las que muestran mayor crecimiento; las empresas de gran tamaño, por su parte, acaparan la generación de la mayor parte del pIB del sector (62\% en 1993), quedando a los pequeños y medianos productores la generación de la mayor parte del empleo (56 por ciento). ${ }^{3}$

En el ámbito geográfico se ha constatado que las áreas protagónicas ya no son solamente las grandes metrópolis asociadas al mercado interno y a la industrialización sustitutiva de importaciones (ciudades de México y Puebla en el centro, Guadalajara en el occidente, y Monterrey en el noreste), con predominio de las ramas tradicionales y maduras y de las vinculadas en forma importante a capitales nacionales; ahora tienen también gran significación las ciudades de los estados del norte del país, asociadas al mercado estadunidense y con importante presencia de ramas modernas, aunque insuficientemente integradas a la economía nacional (Olivera, 1997b). ${ }^{4}$

El propósito de este trabajo es, en primer término, acotar los alcances y las limitantes que para el desarrollo económico y la articulación del sector manufacturero de México tiene el dinamismo exportador alcanzado desde la segunda mitad de los años ochenta en función del que desarrollan diferentes tipos de ramas industriales; asimismo, mostrar la desigual y aún limitada participación de México en los flujos de inversión y comercio mundiales en función de los determinantes externos e internos al país. En una segunda parte se aborda la reconfiguración de la geografía industrial por medio de la distribución territorial por ramas (4 dígitos) del auge exportador, para lo cual se ubica a las ramas de actividad que comandan las exportaciones manufactureras y se determina su peso en el empleo y en el PIB manufacturero. Con el fin de contrastar el comportamiento

\footnotetext{
${ }^{3}$ Otra muestra no menos importante de la fuerte desigualdad interindustrial es el hecho de que únicamente $15 \%$ de las empresas del padrón de exportadoras da cuenta de $80 \%$ de las ventas al exterior.

${ }^{4}$ La conformación de nuevas metrópolis (con más de 500000 habitantes), sin embargo, más que constituir un proceso de descentralización territorial representa una concentración urbana policéntrica, organizada todavía alrededor de tres grandes regiones hegemónicas con centro en las ciudades de México, Guadalajara y Monterrey (véase Garza, 1998: 280-283). Algo similar se advierte en otras ciudades de América Latina como Santiago en Chile y Buenos Aires en Argentina (véase De Mattos, 1999; Ciccolella, 1999).
} 
económico de las diferentes ramas del sector y de comprobar que la apertura comercial y el fomento a las exportaciones están configurando un nuevo mapa industrial en México, se compara la aportación a los indicadores mencionados de las ramas manufactureras "no exportadoras" con la de las "exportadoras"; en estas últimas se distingue además entre ramas exportadoras "líderes" o "modernas", "tradicionales" y "otras exportadoras". Del mismo modo, se presentan algunas consideraciones sobre los aportes que cada uno de estos grupos de industrias puede proporcionar para alcanzar un sector manufacturero mejor articulado, y complementario con los otros sectores económicos. El periodo considerado abarca los años 1980 a 1997 , cuando se dan y consolidan los cambios económicos e institucionales de la transición económica y territorial en curso.

En la última parte se presentan algunos señalamientos relacionados con las implicaciones de política industrial que tiene el comportamiento espacio-sectorial de la industria en el país en los últimos años.

\section{Los supuestos}

Se parte de la certeza de que la geografía de la producción y el grueso de los flujos del comercio internacional están estrechamente ligados, y de que la posición central o periférica que los distintos países tienen, apoyada en la capacidad de los empresarios y el Estado para incidir en ello -aunado a factores históricos y culturales- resulta clave para la construcción y sostenimiento de la competitividad tanto de las empresas en lo individual como del conjunto del sector manufacturero en cada nación.

En términos espaciales o de la división internacional del trabajo, si bien se asume que un esquema centralizado en lo geográfico y lo económico no es compatible con una opción de crecimiento que se sustente en la búsqueda de eficiencia y competitividad mundiales, y que lo más importante no es producir todos los componentes de un producto en un mismo sitio, sino tener acceso a ellos en dondequiera que se produzcan a los costos más bajos posibles (Trejo, 1987: 244), también se considera que para alcanzar un desarrollo nacional armónico es fundamental mantener el control interno de la orientación estratégica de los procesos productivos. Esto último no se desarrolla en el presente trabajo, pero los aportes de otras investigaciones sí permiten exponer algunos comentarios al respecto. 
Para ahondar en los determinantes del cambiante mapa mundial de manufacturas, se asume la posición de Storper (1993: 5), quien habla de territorialización de la producción, la cual ocurre cuando la viabilidad económica de las actividades depende de su localización (pplace-dependence) en un lugar específico arraigado en prácticas y recursos no disponibles en otros lugares o que no pueden fácil ni rápidamente ser creados o imitados. Generalmente las actividades clave, como son las que requieren de alta calificación, conocimiento o contenido de tecnología, están territorializadas en áreas centrales; pero al mismo tiempo que conforman redes de relaciones con otros centros también territorializados, desterritorializan parte de la producción no clave en lugares no centrales. De manera que territorialización-desterritorialización constituyen un mismo proceso en los sistemas de producción globalmente distribuidos.

Ahora bien, dicho proceso puede ocurrir en el interior de un sólo país, pero lo común es que involucre a varios; en este sentido los beneficios se distribuyen de diferente manera -como ya se dijosegún se participe como centro o como periferia. Es claro que los resultados son favorables para el centro, ya que las formas en que se organiza la división espacial del trabajo y se estructuran sus redes de intercambio son funcionales a sus necesidades; los ingresos generados se revierten in situ en la investigación y fortalecimiento de las actividades "motor" intensivas de conocimiento, que además tienen efectos multiplicadores al construir una base amplia de industrias de apoyo, proveedoras de insumos de la calidad y precio requeridos.

Por el contrario, para la periferia los beneficios van de más a menos debido a que les son transferidas principalmente actividades secundarias del proceso productivo, altamente intensivas en mano de obra y poco creadoras de valor agregado (véase ONUDI, 1996: cap. 2), con escasa creación de vínculos interempresariales que no dan origen a raíces territoriales y sin posibilidad de retener excedentes que creen un círculo virtuoso de crecimiento. ${ }^{5}$ De tal manera que es importante promover un desarrollo industrial desde adentro.

${ }^{5}$ Aquí nos referimos sobre todo al caso latinoamericano, pues se reconoce que en el mejor momento de los "tigres asiáticos" sí hubo acumulación de capital, acompañada de una sucesión sectorial de ramas intensivas en mano de obra a otras como la electrónica que incorporan mayor densidad tecnológica; incluso hubo capacidad de reinversión en áreas periféricas de Asia (véase Bustelo, 1992). 
Las cifras para la producción manufacturera y el comercio mundiales muestran claramente la correspondencia entre ambos fenómenos económicos: los principales países productores son los principales exportadores. Pero además, en los países exportadores periféricos, en cuya planta productiva nacional un alto porcentaje corresponde a partes desterritorializadas de países centrales, las exportaciones manufactureras se caracterizan por su alto contenido de insumos importados (véase Vidal, 2000: 587). De acuerdo con Loria (1999: 230), la manufactura mexicana ya constituye una fase más (eslabón) de la estructura de la oferta -más que de la demanda- de la industria de Estados Unidos.

No obstante, si se partiera de la idea y las evidencias de modelos de crecimiento que basen su nivel exportador en las capacidades productivas nacionales (es decir con predominio de una base económica, territorializadas dentro de sus propias fronteras), habría entonces que poner a discusión el modelo económico, de política industrial y de comercio exterior que sustentan tales experiencias, con el fin de aprender de ellas. Asimismo, la única posibilidad de revertir las desventajas de la situación periférica de México en la producción y el comercio mundiales, y de extraer los mayores beneficios de la nueva geografia de la producción que experimenta, es reconocer en qué medida la forma de interrelacionarse con el mundo de este momento le es favorable o desfavorable y qué sería necesario modificar para que el balance fuera positivo.

Algunos autores (Ros, 1997) opinan que la posición de México en la economía mundial debiera merecer mejor suerte, ya que reúne condiciones básicas para ello, como son: un ingreso medio, fuerza de trabajo calificada, infraestructura, avanzado proceso de liberalización, cambios institucionales como el Tratado del Libre Comercio con Estados Unidos y Canadá, y una ubicación geográfica estratégica. Lamentablemente -se opina- su desempeño económico ha sido decepcionante, ya que el país no cumple con otras características fundamentales y porque se han elegido opciones erróneas cuyo resultado es una inserción problemática que acentúa las desigualdades socioeconómicas. A ello cabría agregar, como una limitante seria, la falta de consenso para respaldar la política económica y por lo tanto de apoyo social.

En la siguiente sección se revisa la participación de México en el comercio y la producción mundiales de manufacturas, con base en que el impulso al comercio exterior tuvo notoriedad en los años 
ochenta y que en ello se basó gran parte de la recuperación de la crisis económica de 1982, junto con la fuerte apertura comercial, la desregulación económica y la política de contención salarial.

Características de la participación de México en el comercio y producción mundiales de manufacturas

Uno de los logros económicos que se atribuye el gobierno mexicano es el dinamismo exportador que desde hace más de diez años muestra el sector manufacturero, y que es considerado también el medio gracias al cual el país se ha insertado en forma aparentemente exitosa en los flujos mundiales de comercio. Entre los hechos que sustentan tal apreciación destacan los siguientes:

1) En primer término se ubica un importante cambio en la estructura de las exportaciones totales: de ser predominantes las de productos basados en recursos naturales como el petróleo, con $61.7 \%$ en 1983, se pasó al predominio de las manufacturas, con $82 \%$ en 1994 . Otros productos primarios cambiaron de 6.6 a $5.5 \%$ en el mismo lapso.

2) La tasa de crecimiento promedio anual de las exportaciones manufactureras durante los años ochenta $(17.9 \%)$ duplicó el promedio internacional. Esto provocó que del lugar 40 que México ocupaba en las exportaciones totales mundiales en 1978, alcanzara la posición 20 en 1989 (Dicken, 1992). Al inicio de 1998 el gobierno mexicano ubica al país como la decimotercera economía del mundo y en el décimo lugar entre los principales exportadores.

3) El coeficiente de exportación (relación entre el valor de las exportaciones y el valor bruto de la producción) aumentó de $3.1 \%$ en los setenta a 10.9\% en 1992 (Bielchowsky y Stumpo, 1995). Asimismo, la suma de importaciones-exportaciones como porcentaje del PIB fue de $24 \%$ en $1985,55 \%$ en 1994 y $58 \%$ en 1998 .

4) Por último, el aumento de las ventas al exterior ha coincidido con un incremento de las corrientes de inversión extranjera directa (IED) hacia el país, cuyos montos en la primera mitad de los noventa se multiplicaron por cinco en relación con 1980; asimismo, México fue el único país de los más industrializados de América Latina que logró atraer capitales en la segunda mitad de los años ochenta, de los cuales una parte importante se dirigió al sector manufacturero.

Ahora bien, no obstante que lo señalado representa cambios estructurales de importancia en la economía mexicana con fines de una 
inserción favorable en la economía internacional, es dificil estar de acuerdo con que al dinamismo exportador manufacturero deba considerársele un éxito. Son ya numerosas las opiniones en el sentido de que sus beneficios han sido exagerados, como lo demuestran el hecho de que la participación de México en el comercio internacional sigue siendo marginal (Vázquez, 1995; Conde, 1996; Casar, 1993), el de que sus exportaciones se concentran en un reducido número de empresas, productos y ciudades o regiones (Unger, 1993; Olivera, 1997a), y de que dicho dinamismo exportador está sustentado no en la capacidad productiva nacional sino en la de corporaciones trasnacionales, lo cual se refleja en un sector industrial desarticulado en lo interno y con los demás sectores, y marcado por agudas desigualdades.

\section{Una participación problemática}

Para que al dinamismo exportador mexicano pudiera considerársele un proceso exitoso, tendría que superar varios problemas, entre ellos los siguientes:

1) Debido al predominio de capital extranjero en las empresas que comandan las exportaciones, no hay incorporación de insumos nacionales en cantidad suficiente para fortalecer las cadenas productivas internas e integrar al sector manufacturero nacional (Vidal, 2000: 589). Por el contrario, ocurre una progresiva desnacionalización de la planta productiva, ya que se está dando de manera ininterrumpida una transferencia de empresas nacionales al capital extranjero vía adquisiciones, fusiones e inversiones. Esto incluye desde bancos, ferrocarriles, telecomunicaciones, seguros, cadenas comerciales, grandes agroindustrias, etcétera. ${ }^{6}$

\footnotetext{
${ }^{6}$ Debilitadas por la más reciente crisis de 1995 y un exiguo mercado interno, las grandes empresas mexicanas que habían superado las crisis anteriores están siendo absorbidas por capital extranjero, principalmente estadunidense. Gigarrera La Moderna, por ejemplo, una gran industria tabacalera, quedó bajo el control de BAT Industries PLC de Inglaterra en una operación de 1500 millones de dólares; Phillips Morris aumentó su participación de 29 a $50 \%$ en Tabacalera Mexicana, otra gran compañía, en una operación de 400 millones de dólares; Wal-Mart Stores tomó el control de CIFRA, la minorista más grande del país, por 1300 millones de dólares; Nheuser Bush esperaba comprar una participación de 50.2\% en Grupo Modelo, que produce la cerveza Corona, por unos 1600 millones de dólares; entidades extranjeras controlan plenamente $15 \%$ de las instituciones bancarias mexicanas; y en ese tenor se realizaron mumerosas operaciones en 1997 (véase la revista Proceso, núm. 1095, 1997).
} 
2) Como corolario de la elevada participación de las maquiladoras en las exportaciones manufactureras ( $49 \%$ del total del sector) y de que éstas concentran una parte importante de los productos modernos y líderes, México está lejos de ser una potencia exportadora y más bien se constituye en un complejo maquilador que beneficia a algunas corporaciones globales, quedando los costos a cargo de la población y los gobiernos locales. El grado de integración de las maquiladoras es tan bajo que del total de insumos que utilizan, únicamente entre dos y tres por ciento es de origen nacional. ${ }^{7}$

3) Si bien en conjunto las maquiladoras y no maquiladoras generaron ingresos brutos de 222342 millones de dólares entre 1983 y 1994 con una tasa de crecimiento media anual (TCMA) de 17.9, por concepto de importaciones erogaron 208038 millones en el mismo periodo (TCMA de 16.0), lo que da un saldo de 14304 millones (véase Vázquez, 1995: 598).

Llama la atención el hecho de que los años con saldo negativo coinciden con aquellos en que hubo reactivación económica (1990 a 1994 y muy próximo al equilibrio en 1997), mientras que los saldos positivos coinciden con los años de ajuste (1983 a 1987 y después entre 1995 y 1996); en el primer caso bajo condiciones de un peso sobrevaluado y en el segundo después de un ajuste en el tipo de cambio.

Ahora bien, si se ajustan los datos de las exportaciones netas a precios constantes del dólar y se considera el conjunto de sectores económicos, las exportaciones tuvieron un crecimiento poco significativo ( $1.1 \%$ de crecimiento promedio anual), contrario a lo que sucedió con las importaciones $(16.0 \%)$; las primeras representaron ingresos por 186065 millones de dólares, y las segundas egresos por 210815 millones, de tal manera que el saldo negativo neto fue de 24750 millones. Del mismo modo, mientras en 1983 de cada dólar de exportación 88 centavos en promedio correspondían a insumos mexicanos (materia prima, mano de obra, partes, componentes, otros insumos), para 1994 esta participación había disminuido a 42 centavos (Loria, 1997: 22); o en valores absolutos, de los casi 35000 millo-

Según Conde (1996: 146), “...las industrias maquiladoras son un apéndice productivo de procesos de acumulación cuyo dinamismo se encuentra en otras economías, [son] empresas cuyos procesos tecnológicos, apoyos financieros y formas de comercialización se encuentran organizados por estructuras corporativas multinacionales desde el punto de vista económico; el sector maquilador es una extensión de los mercados internos de otras economías". 
nes de dólares brutos exportados en el periodo, únicamente 3000 fueron los realmente exportados por México.

En síntesis,

[...] el volumen creciente de comercio exterior no está asociado a mayor generación de divisas, sino lo contrario; cuando lo deseable sería que aumente éste saldo aun cuando no necesariamente aumente el volumen total intercambiado [...] Un verdadero logro macroeconómico sería que a cualquier nivel de comercio exterior se generaran superávit comerciales altos y crecientes (Vázquez, 1995).

\section{Unaiparticipación desigual}

Según datos del Banco Interamericano de Desarrollo (BID) (1992), las exportaciones de los países industrializados representaban más de $90 \%$ del comercio mundial manufacturero en 1990 , con todo y que habían crecido a menos de la mitad que en los países recientemente industrializados de Asia. Estos últimos aumentaron su participación de $2 \%$ al iniciar los setenta a más de $6 \%$ en la segunda mitad de los ochenta, mientras que los industrializados bajaron de 97 a $92 \%$ (con una tasa de crecimiento de $6.3 \%$ ). Aunque en Latinoamérica se duplicó la tasa de crecimiento (11\%) de los países industrializados, aún resultó inferior a la de las principales economías asiáticas (15\%); por lo tanto su participación todavía es pequeña y podría ser incrementada.

La primacía de los países industrializados en las exportaciones es más notable al desagregarlas según su densidad de capital (maquinaria eléctrica, equipo de transporte, equipo profesional y científico) o de mano de obra (alimentos, bebidas, textiles, prendas de vestir). Las primeras -con un crecimiento importante de $4.0 \%$ en 1995 , contra $3.1 \%$ de las segundas- dominan el valor manufacturero mundial (23.2\% por $18.2 \%$ de las tradicionales) y se localizan principalmente en dichas naciones y en menor medida en las economías emergentes.

En cuanto al valor agregado manufacturero (VAM), el conjunto de países en desarrollo alcanzó una participación de $20 \%$ en el total mundial en 1995. Pero el crecimiento se repartió desigualmente: Asia oriental y sudoriental han sacado ventaja, en tanto que África subsahariana está marginada. América Latina, mientras tanto, redujo su participación en el VAM mundial y más aún entre los países en desarrollo: de 37 a $24 \%$ entre 1985 y 1995. De esta manera, el VAM que se ha desplazado 
de los países del primer mundo no ha tenido a Latinoamérica como beneficiario principal (ONUDI, 1997). México, por ejemplo, participó con $1.5 \%$ del VAM mundial en 1985 , y $0.8 \%$ en 1990 y 1995 .

Por lo que atañe a la inversión extranjera, ésta subyace en la dinámica del crecimiento industrial y la modernización tecnológica. Sin embargo, existen algunas variantes: únicamente cuando se trata de IED hay creación o ampliación de la capacidad productiva y se generan utilidades; cuando es inversión de cartera o portafolios no necesariamente implica mayor capacidad productiva y lo que genera son dividendos o intereses (Vera, 1996: 130). Un tipo de inversión directa a largo plazo es considerada como estímulo real al desarrollo de la planta productiva del país receptor, mientras que una inversión predominantemente de cartera y a corto plazo es vista como factor de riesgo. El saldo para América Latina y México aun cuando ha significado un cambio notable en la estructura de las economías nacionales, no es del todo favorable.

Durante los últimos años ha predominado en América Latina la inversión privada de capital extranjero: ya en 1990 representaba dos tercios y en 1994 superaba $95 \%$ del total. Pero el cambio principal fue que la inversión de cartera pasó de 4 a $42 \%$ en los mismos años, con un máximo en 1993 (62\%) y el predominio de la inversión de corto plazo; esta última superó $70 \%$ a fines de los ochenta para reducirse a $58 \%$ en 1994. Peor aún, más de $40 \%$ de la IED en la región entre 1988 y 1993 fue producto de programas de reconversión de deuda externa y privatizaciones (Vera, 1996: 133), con lo cual la inversión real resulta bastante menor. Esta grave ausencia de ahorro interno y predominio de inversión extranjera de corto plazo, en combinación con una política cambiaría de sobrevaluación, mostró sus efectos negativos en la crisis mexicana de fines de 1994.

Cabe reconocer que más de $60 \%$ del comercio mundial de manufacturas y cerca de $85 \%$ de las corrientes mundiales de IED en 1995 ocurrieron entre países industrializados (ONUDI, 1996: 15). En tanto, en Latinoamérica las tasas de inversión interna bajaron de $19.6 \%$ en los primeros años de los ochenta, a $18.5 \%$ en la primera mitad de los noventa (frente a 27.3 y $31.7 \%$ en Asia oriental). Al mismo tiempo las tasas de ahorro están disminuyendo en la región y son más bajas que las tasas de inversión, lo cual pone en duda la capacidad de lograr un desarrollo sostenido (ONUDI, 1996: 19).

La desigual participación de las naciones en los flujos de inversión y comercio, entre otras causas, sostiene la nueva división interna- 
cional del trabajo. Lo principal, sin embargo, es crear ventajas comparativas dinámicas; y aquí la capacidad competitiva no depende de un solo factor ni está dada para siempre. Más que con la disponibilidad de recursos y el precio del producto, la competitividad tiene que ver con la calidad de los recursos humanos y la capacidad para absorber y difundir avances tecnológicos. Asimismo, es fundamental la capacidad de los empresarios para construir vínculos internacionales con proveedores de insumos, de servicios, con inversionistas e instituciones científicas y de investigación (ONUDI, 1996). No puede olvidarse por supuesto la acción estatal; de hecho, la causa del desempeño desigual de la industrialización de los NlC's asiáticos y los países de reciente industrialización en América Latina se atribuye a la diferente concepción de lo que debe ser la promoción de las exportaciones. Los países orientales ${ }^{8}$ combinaron un tipo de cambio real alto y estable con el uso de protección a industrias nacientes; se apoyó la liberalización de importaciones y se impulsó el desarrollo de los factores productivos junto con el ahorro y la inversión (Ros, 1997). Los grandes países latinoamericanos han combinado apertura económica con apreciación cambiaría, liberalización financiera plena, bajas tasas de ahorro e inversión y escasos esfuerzos por promover políticas sectoriales de apoyo (Ros, 1997)

\section{Distribución sectorial y regional del dinamismo exportador}

Uno de los efectos de la apertura comercial que se realizó en 1986 fue la polarización de la capacidad competitiva de los diversos sectores y ramas de la industria; una minoría logró adaptarse a las nuevas condiciones de competencia internacional, mientras que la mayor parte vio caer su producción y empleo (véase Dussel, 1995). La política de contención salarial y de austeridad, combinada con la inflación galopante, constituyó un contexto absolutamente negativo para la recuperación.

El sector exportador de la industria no escapa a la polarización, de ahí que lo distingan su alta concentración en términos de productos de empresas y de mercado de ventas. En cuanto a productos, por

\footnotetext{
${ }^{8}$ Se está haciendo referencia a la situación previa a los graves problemas que sufrieron los países asiáticos a fines de 1997.
} 
ejemplo, cincuenta de ellos representan $75 \%$ de las exportaciones y quince $50 \%$; en cuanto a tamaño de los establecimientos, domina un grupo relativamente pequeño de grandes empresas; y en cuanto a destino, a Estados Unidos se dirige $85 \%$ de las ventas en promedio.

Ahora bien, aunque el interés particular de este trabajo es el comportamiento regional y por ramas de las exportaciones, resulta apropiado presentar una muy breve semblanza del sector manufacturero en general, que servirá como punto de referencia al abordar ramas de actividad específicas.

Una primera referencia al total del sector es que, no obstante la caída de la tasa de ganancia y el cierre de empresas, se crearon entre 1980 y 1993, más de un millón cien mil empleos manufactureros en todo el país, con una tasa de crecimiento de $3.2 \%$, superando al $2.0 \%$ con que creció la población en el mismo lapso. Aunque debe mencionarse que $55 \%$ de dichos empleos se creó entre 1988 y 1993, y el resto entre 1980 y 1987 ; es decir, cuando la apertura fue más grande. Un dato revelador de la mayor adversidad para el crecimiento industrial en la primera parte de los años ochenta es que entre 1982 y 1986 hubo desindustrialización al llegar el producto interno bruto (PIB) manufacturero a una tasa de crecimiento promedio anual de $-0.7 \%$ (véase Rueda, 1995: 150).

Otros indicadores también demuestran el mayor dinamismo del periodo 1988-1993 en comparación con el comprendido entre 1980 y 1987. En cuanto a establecimientos, por ejemplo, de $108 \%$ que crecieron entre 1980 y $1993,8.7 \%$ se dio en la primera mitad, contra $91.4 \%$ en la segunda; para las remuneraciones la relación fue de -21.4 y $86.8 \%$ respectivamente; para el valor de la producción fue de 10.8 y $51.3 \%$; y para el PIB, de 17.4 y 50.1 por ciento.

Entre las distintas fases de crisis y ajuste, sin embargo, el rostro de la industria manufacturera, como el de la economía en general, no fue el mismo. En términos de valor agregado, algunas divisiones se vieron beneficiadas y otras resultaron perdedoras. En el subsector industrial, por ejemplo, los cambios de 1982 a 1994 consistieron en la reducción del dinamismo de algunos de los considerados tradicionales: la confección -que fue la más afectada en un principioy la madera y productos de madera, tuvieron tasas negativas de crecimiento; las industrias de papel-imprenta-editoriales, metálicas básicas, minerales no metálicos, y otras, alcanzaron tasas de crecimiento positivas pero inferiores a la media nacional; por su parte, los alimentos, sustancias químicas y productos metálicos, maquinaria y 
equipo, crecieron por arriba del promedio. En general, retroceden los bienes de capital y de consumo durable para el mercado interno, y crecen las actividades de exportación, sobre todo la maquila (Rueda, 1995: 158).

Un aspecto notable de los cambios cualitativos es el de las ocupaciones, donde los nuevos empleos no son igual a los que se pierden. Ello lo ilustra la situación posterior a la última gran crisis de 19941995. Así, de acuerdo con cifras del Instituto Mexicano del Seguro Social (IMSS), de los 750000 empleos creados en 1997, considerado como un año de crecimiento económico, $90 \%$ corresponde a ingresos de entre uno y dos salarios mínimos (entre 26 y 52 pesos diarios, o entre 3.2 y 6.5 dólares al tipo de cambio promedio del año) (véase el periódico El Financiero, 26 de diciembre de 1997). En el caso exclusivo del ámbito urbano, $47.5 \%$ de los nuevos empleos corresponde a menos de 1 y hasta 2.5 salarios mínimos; si se suman los trabajadores sin ingresos y los no especificados, $56.7 \%$ del nuevo empleo urbano del primer cuatrimestre del año referido fue de ínfima calidad.

En suma, aun cuando el periodo de mayor apertura económica tiene como resultado una recuperación del sector manufacturero, ésta es cuestionable por haber incrementado las desigualdades entre los distintos tipos de industria, reducido la calidad del empleo, polarizado el mercado de trabajo, cambiado las relaciones laborales, y contribuido a una profunda desintegración del sector.

\section{Cambios en la localización}

Destaca en primer término la pérdida absoluta de 94804 empleos industriales en el Distrito Federal entre 1980 y 1993, lo cual hace que esta entidad baje más de 12 puntos porcentuales en su participación nacional. También disminuyen su participación en forma importante el Estado de México y los de Nuevo León y Veracruz. Las cuatro entidades contenían $57.3 \%$ (1 226 911) de los empleos del sector en 1980 y sólo 39.8\% (1 290459 ) en 1993. Por el contrario, entidades como Aguascalientes, Baja California, Coahuila, Chihuahua, Guanajuato, San Luís Potosí, Sonora y Tamaulipas, que generaban $17.3 \%$ (370 163) de los empleos en el primer año, llegaron a 30.8\% (994 318) en el último (mapa 1).

Este surgimiento de "nuevos" centros de crecimiento industrial representa una descentralización de la actividad industrial en el terri- 
MAPA 1

Empleo creado en la industria manufacturera por entidad federativa, entre 1980 y 1993

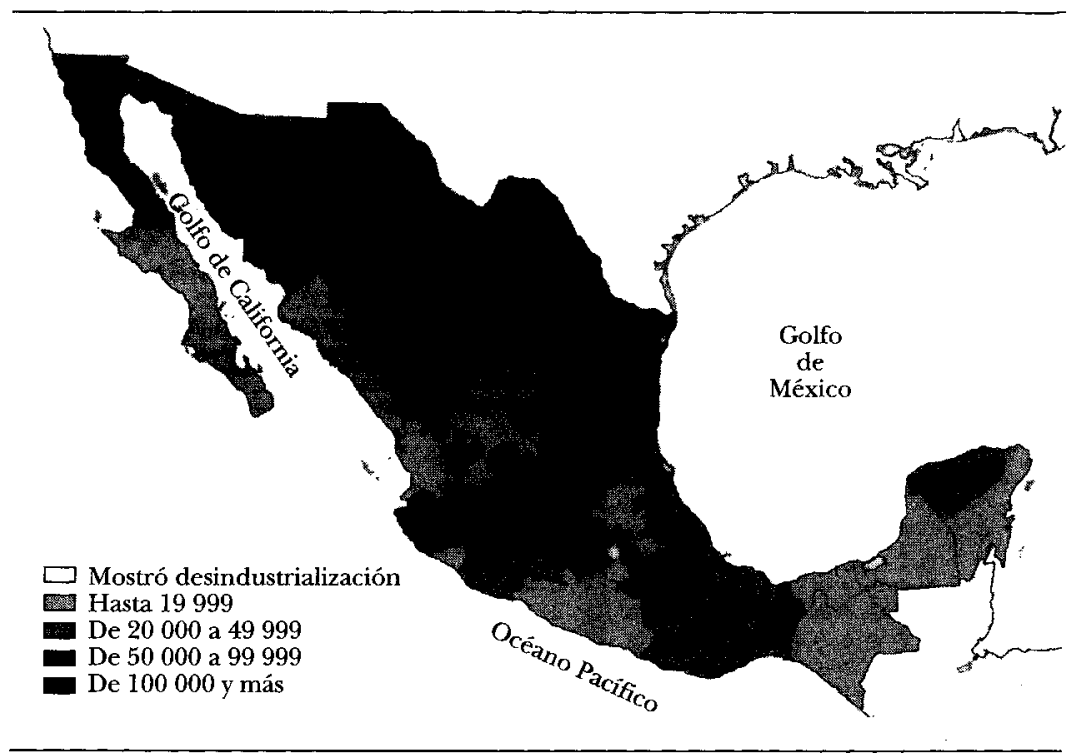

Fuente: INEGI, Censos Industriales.

torio nacional, al mismo tiempo que la consolidación de dos grandes áreas de crecimiento. Aunque, como se ha dicho, es producto en gran medida de la inserción de México en la división internacional del trabajo y de las corrientes de comercio exterior; por lo que responde más a decisiones exógenas que a un fortalecimiento de la capacidad productiva del país, y sólo en alguna medida a las políticas industriales del Estado. No puede ignorarse, desde luego, la activa participación de los grupos empresariales locales fronterizos en la concreción de dicha dinámica.

Enseguida se profundiza en el efecto de la apertura comercial y la promoción de las exportaciones sobre la relocalización de la actividad manufacturera, el dinamismo de las exportaciones a nivel de rama y los cambios en la productividad y la competitividad con los que están asociados. 
Distribución de las exportaciones por rama de actividad

Según Unger (1993: 185), si se toma en cuenta el dinamismo tecnológico de las industrias, éstas forman tres grupos: las industrias modernoinnovadoras, las industrias maduras y las industrias basadas en recursos naturales.

Industrias moderno-innovadoras. Enfrentan una fuerte reestructuración competitiva en el mercado mundial, participan con casi la mitad de las exportaciones manufactureras recientes. Aquí se ubican los automóviles y autopartes, computadoras, materiales plásticos y resinas, películas y barras de hierro, máquinas de oficina y química. Su comercio es realizado por subsidiarias de empresas trasnacionales, por lo que se trata de un comercio predominantemente intraindustrial. Destaca la industria automotriz, que representa la tercera parte del comercio total manufacturero del país.

Industrias maduras. Han aumentado su participación en las ventas foráneas, alcanzando una cuarta parte del total. Han adquirido importancia gracias a las ventajas comparativas dinámicas que les ha proporcionado la absorción de tecnología difundida desde el exterior. Son las del vidrio y productos de vidrio, productos de hierro y acero, cemento, juguetes, artículos deportivos y algunos tintes y barnices. A diferencia de los otros dos grupos tienen un mercado de ventas más diversificado. Aunque algunas de estas industrias constituyen monopolios nacionales, las dos primeras participan con una cuarta parte de las exportaciones del total de este grupo.

Industrias basadas en recursos naturales. Son consumidoras de tecnología, han disminuido su participación desde $50 \%$ en 1982 a $33 \%$ al inicio de los noventa. Se trata de alimentos y bebidas, textiles y confección, madera, papel y minerales. Involucran transacciones entre agentes comerciales independientes entre sí y enfrentan una amplia competencia de productores en Estados Unidos, razón por la que ha disminuido el volumen de sus exportaciones. También hay marcada heterogeneidad en su tamaño y capacidad tecnológica.

A partir de los tres grupos anteriores, se puede dividir al conjunto de la actividad manufacturera nacional en ramas exportadoras y no exportadoras. Del grupo de las exportadoras a su vez se desprenden las ramas líderes, las tradicionales, y “otras”. Las ramas exportadoras líderes son las de vehículos, autopartes, maquinaria no eléctrica, hierro-acero, maquinaria eléctrica e industria química; las cuales participaban con $67.4 \%$ de las exportaciones en 1991, cuando entre 1975 y 1981 lo hacían 
con menos de $40 \%$ (cuadro 1); las industrias tradicionales son alimentos, bebidas, textil y confección, papel y minerales, que redujeron su participación de 36.7 a 17.7. "Otras industrias exportadoras" constituyen un grupo más amplio, pero sólo participaban con $14.9 \%$ en $1991 .^{9}$

\section{Contribución de las diferentes ramas exportadoras en los establecimientos, el empleo y el PIB manuifacturero}

Es importante considerar que los datos de establecimientos, empleo y PIB para cada uno de los grupos son aproximados, puesto que las fuentes que indican exportaciones no consideran dichos aspectos; no obstante sí permiten identificar a grandes rasgos cómo contribuyen dichas ramas en cada uno de tales indicadores y cuál es su distribución espacial en el país.

Según se muestra en el cuadro 1, en 1993 es mayor la cantidad de establecimientos manufactureros en las ramas no exportadoras que en las exportadoras, aunque en estos últimos laboran dos terceras partes del total de trabajadores; ello se debe a que, en general, son unidades de tamaño casi tres veces mayor que el de las no exportadoras. Las variaciones ocurridas entre 1980 y 1993 indican poca probabilidad de cambio en los años posteriores.

Un desglose de los diferentes tipos de ramas exportadoras indica que la importancia de las ramas líderes en el total de exportaciones no tiene correspondencia con el número de establecimientos involucrados ni con los empleos que generan. Si bien aportaban $63.4 \%$ de las ventas al exterior en 1991, sólo involucraban $3.4 \%$ de los establecimientos y aportaban $17 \%$ del empleo en 1993; estas cifras son aún menores que las de 1980, y resultan de la concentración técnica que experimentan las unidades productoras, pues el número promedio de trabajadores por cada una es de 60.8 , muy superior al de las otras

\footnotetext{
${ }^{9}$ Las industrias enlistadas corresponden a las siguientes ramas de los censos industriales: 1) ramas exportadoras líderes: $3512,3710,3822,3823,3831$ y 3841,2 ) ramas exportadoras tradicionales: $3113,3130,3140,3212$, 3213, 3220, 3230, 3311, 3410, 3611 , 3612,3620 y 3691 ; 3) otras exportadoras: $3211,3240,3320,3511,3513,3540,3560$, $3720,3814,3821,3832,3833,3842,3850$ y $3900 ; 4)$ ramas no exportadoras: 3111,3112 , $3114,3115,3116,3117,3118,3119,3121,3122,3214,3312,3420,3521,3522,3530$, $3550,3811,3812$ y 3813 . Si bien esta clasificación constituye un ejercicio modesto, los resultados ofrecen un panorama bastante interesante del comportamiento diferenciado de la manufactura.
} 


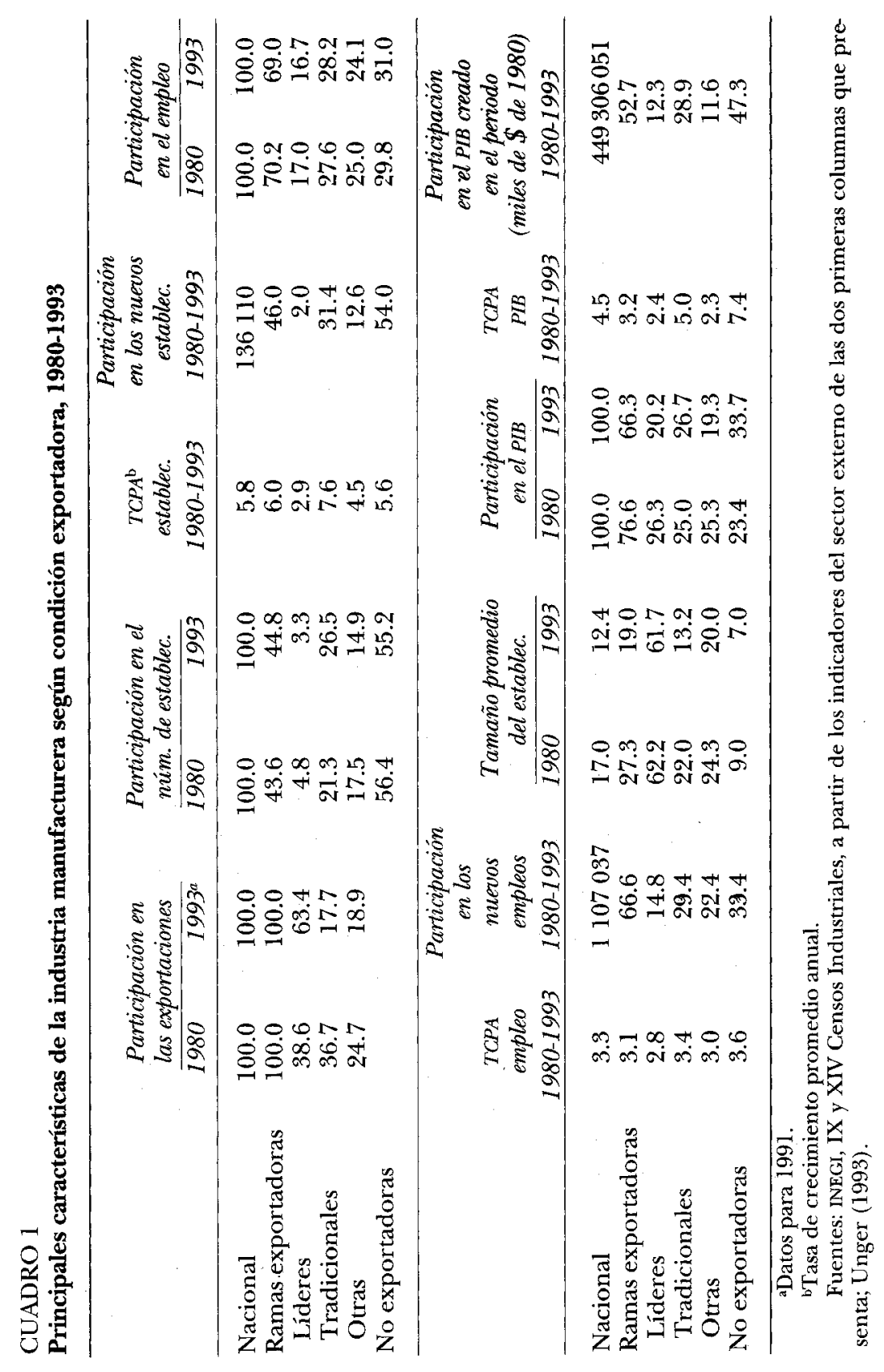


ramas. El mayor peso social correspondía a las ramas tradicionales y después a "otras", donde se hallaba 26.4 y $15.4 \%$ de los establecimientos y 28.2 y $24.1 \%$ del empleo, respectivamente, en 1993.

En cuanto al PIB, si bien las ramas exportadoras aportaban $66.3 \%$ contra $33.7 \%$ de las no exportadoras en 1993, el mayor aporte lo hacían las exportadoras tradicionales (26.7\%), seguidas por las líderes $(20.2 \%)$ y "otras" (19.3\%); debe resaltarse, no obstante, que con relación a 1980, las ramas no exportadoras y las exportadoras tradicionales aumentaron su participación a costa de las exportadoras y de las exportadoras líderes; en ese mismo orden, sus tasas de crecimiento respectivas han sido de 7.4, 5.0, 3.2 y 2.4 por ciento.

Ahora bien, lo anterior ha sido suficiente para modificar el mapa nacional de la industria, como se mostrará en la sección siguiente.

\section{El cambiante mapa nacional del empleo manufacturero}

Distribución por entidad federativa

En el cambio total ocurrido entre 1980 y 1993 nueve entidades absorbieron $71.3 \%$ de los nuevos empleos, cada una aportó entre 50000 y 100000 (cuadro 2a y mapa 1). Éstas son: Baja California, Coahuila, Chihuahua, Guanajuato, Jalisco, México, Nuevo León, Puebla y Tamaulipas; siendo Nuevo León y Chihuahua las que se ubican en los extremos: la primera con 55361 empleos y la segunda con 163282. No es despreciable, sin embargo, el aporte de Aguascalientes, Michoacán, San Luís Potosí y Sonora, con más de 30000 cada uno.

Con excepción de Jalisco, Nuevo León y México, que perdieron peso relativo, los demás estados aumentaron notablemente su participación en el total nacional. Esta situación se asemeja a los cambios que experimentaron años atrás los viejos centros industriales de los países desarrollados, ya que junto con el Distrito Federal, que tuvo pérdidas totales de 94804 empleos, coinciden en esa situación las tres grandes metrópolis del país (Ciudad de México, ${ }^{10}$ Monterrey y Guadalajara); éstas fueron las ciudades más dinámicas en el periodo de

${ }^{10}$ En la Zona Metropolitana de la Ciudad de México la reestructuración ha sido más severa, como lo muestra la desindustrialización absoluta que, en términos de empleo, experimentó en los trece años del periodo analizado. La generación de 76804 empleos en el Estado de México no compensó la pérdida de 94804 en el Distrito Federal. 
sustitución de importaciones y ahora, con la apertura comercial, han entrado en un proceso de reestructuración (principalmente las dos primeras) que aún no concluye. ${ }^{11}$ Parece clara hasta ahora la coexistencia de dos grandes regiones de desarrollo industrial: una en la franja norte del país y otra en la porción central. Los distintos estados del sur, mientras tanto, con excepción de la península de Yucatán, no se incorporan de lleno a la industrialización.

Ramas exportadoras y no exportadoras. Destacan dos grupos de entidades (mapas 2 y 3): el que conforman Baja California, Coahuila, Chihuahua, Sonora y Tamaulipas; y el que corresponde a Guanajuato, Jalisco, Estado de México, Nuevo León, Puebla y Veracruz; en cada caso corresponden a los lugares de reciente y antigua industrialización, y también en términos generales a los dos áreas territoriales mencionadas, con excepción de Nuevo León, que siendo un estado norteño también es un antiguo polo industrial. En el primer grupo de entidades se localiza $55.8 \%$ de los nuevos empleos en ramas exportadoras (mapa 2) y 12\% de las no exportadoras; en el segundo grupo los datos son 30.3 y $46.6 \%$. E1 Distrito Federal, como caso aparte, muestra valores positivos únicamente en las ramas no exportadoras (mapa 3), aunque con una participación de apenas 2 por ciento.

Ramas exportadoras líderes. Continuando con la agrupación anterior, los datos de estas ramas muestran con claridad la desindustrialización relativa que se presenta en el país (mapa 4). En el primer grupo se generó $99.8 \%$ de los empleos; el segundo, por su parte, decreció 1.2 unidades porcentuales. Yisi se añade el Distrito Federal, el descenso fue de casi 19 puntos.

Ramas exportadoras tradicionales. Aquí las entidades de reciente industrialización participaron con $28 \%$ de los empleos, mientras que las de antigua industrialización lo hicieron con $39.8 \%$ (mapa 5). En estas ramas el Distrito Federal tuvo un decrecimiento de 10.9 por ciento.

"La similitud con los países del primer mundo se mantiene, si se considera que después del proceso de desindustrialización y desconcentración que vivieron las grandes aglomeraciones urbano-industriales en los años setenta -acompañado por la industrialización y concentración en zonas de menor desarrollo relativo-, experimentaron nuevamente una reindustrialización y reconcentración a partir de los ochenta (véase autores indicados en la nota 1, así como Guadarrama, 1995). El Distrito Federal, por ejemplo, se recuperó de la desindustrialización que sufrió en los ochenta, ya que en la primera mitad de los noventa volvió a presentar números positivos. Su recuperación en el PIB, mientras tanto, fue mayor. 
MAPA 2

Empleo creado en las ramas manufactureras exportadoras por entidad federativa, entre 1980 y 1993

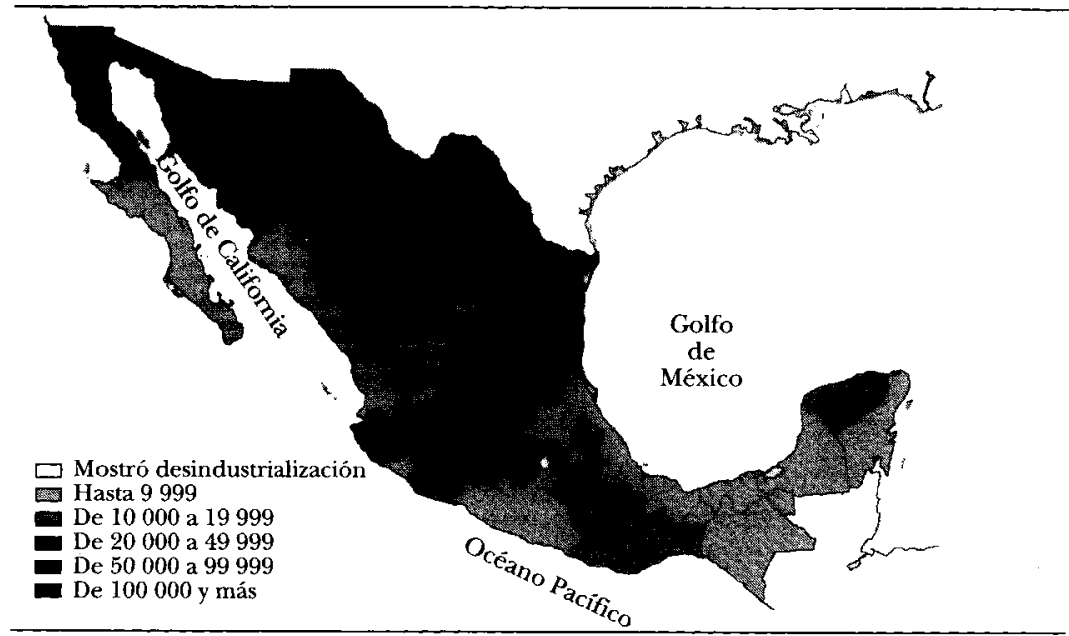

Fuente: INEGI, Censos Industriales.

MAPA 3

Empleo creado en las ramas manufactureras no exportadoras por entidad federativa, entre 1980 y 1993

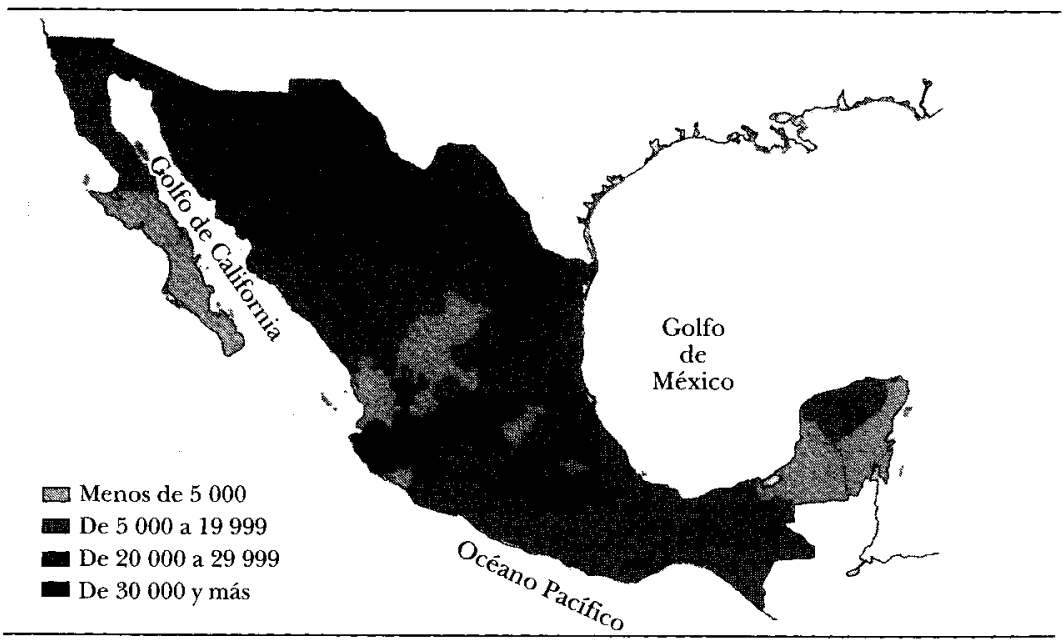

Fuente: INEGI, Censos Industriales. 


\section{MAPA 4}

Empleo creado en las ramas manufactureras líderes por entidad federativa, entre 1980 y 1993

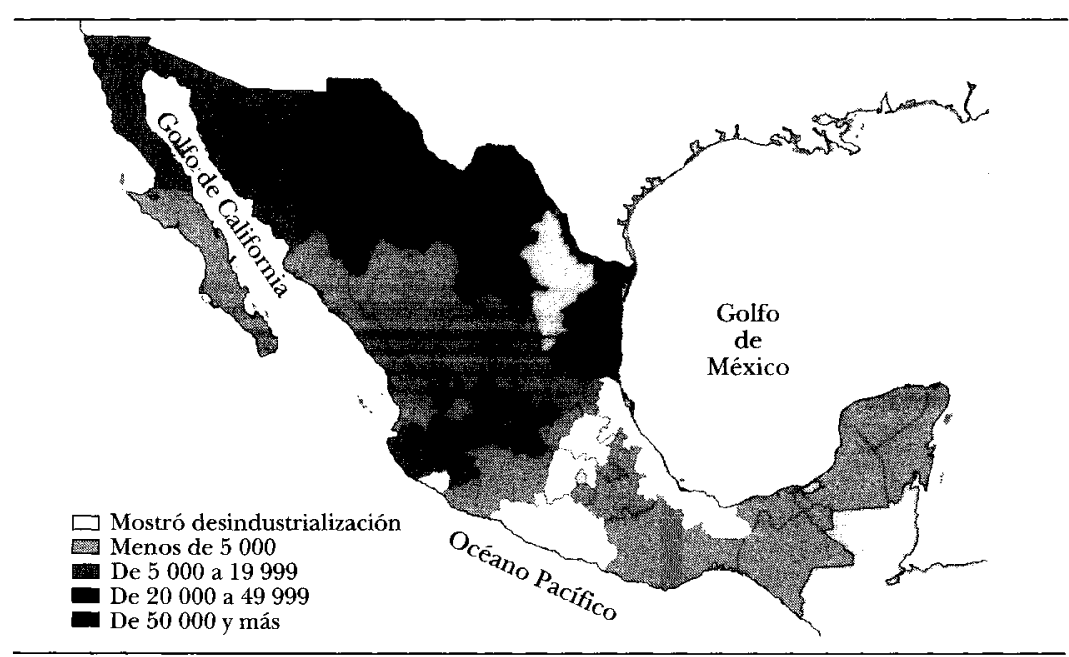

Fuente: INEGI, Censos Industriales.

MAPA 5

Empleo creado en las ramas manufactureras exportadoras tradicionales por entidad federativa, entre 1980 y 1993

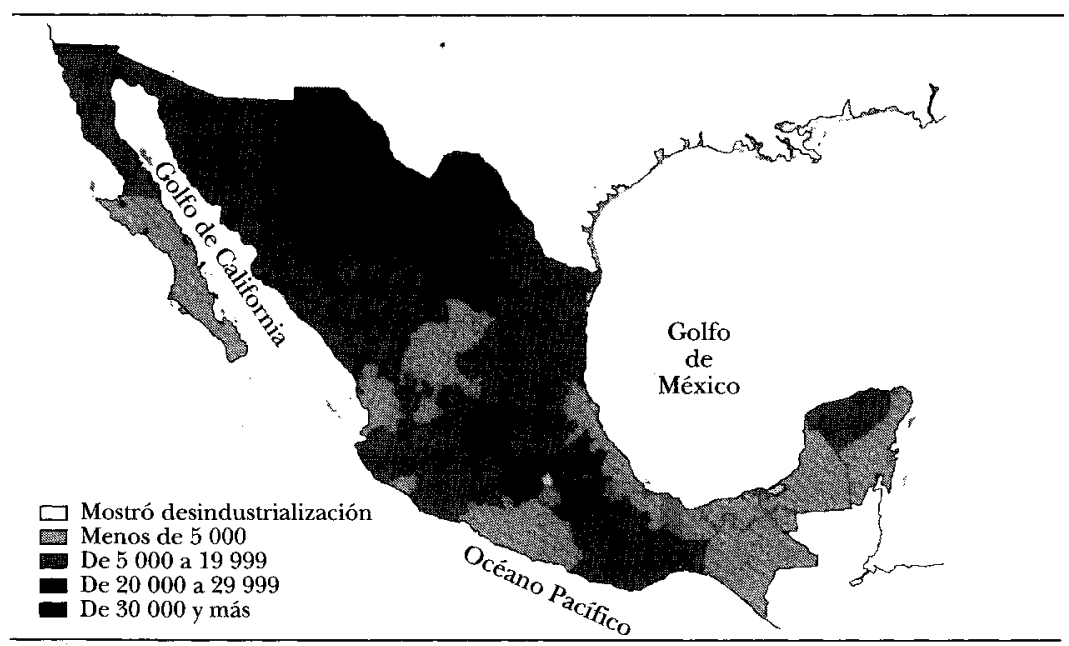

Fuente: INEGI, Censos Industriales. 
MAPA 6

Empleo creado en las otras ramas manufactureras exportadoras por entidad federativa, entre 1980 y 1993

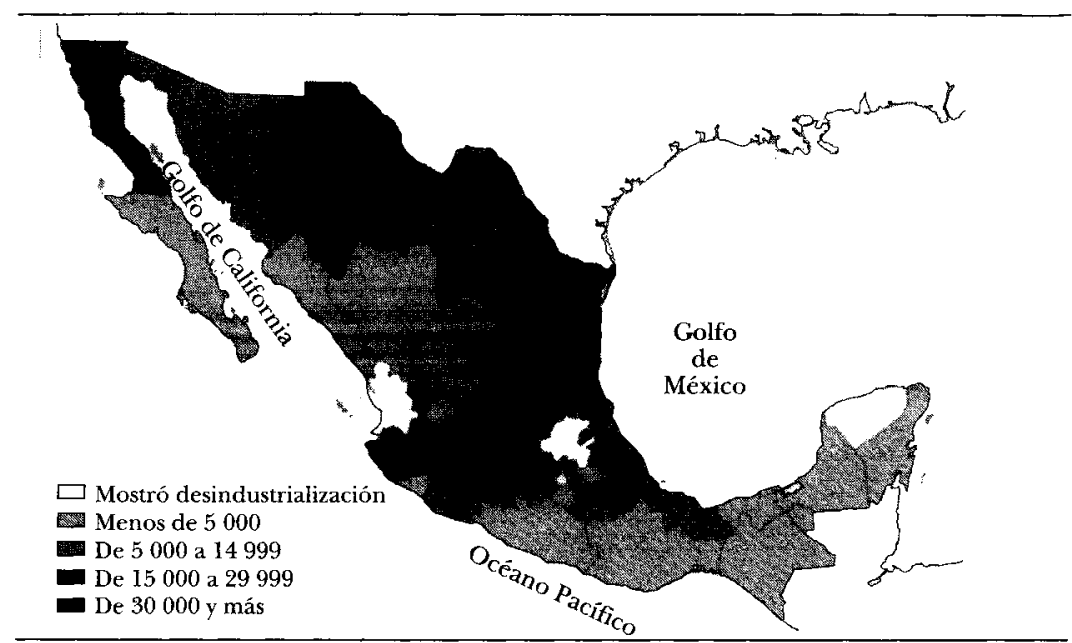

Fuente: INEGI, Censos Industriales.

Otras ramas exportadoras. Nuevamente el primer grupo mostró mayor dinamismo (mapa 6), aportó $63.7 \%$ de los nuevos empleos, mientras que el segundo grupo sólo 24\%. El Distrito Federal perdió 15.3 unidades.

\section{Distribución por regiones ${ }^{12}$}

Con una tasa de crecimiento promedio anual de $3.3 \%$ en el periodo de referencia, para el empleo total del sector manufacturero, el mayor dinamismo le correspondió a las regiones Norte, Noroeste y Cen-

${ }^{12}$ Las regiones consideradas son las siguientes: región Noroeste: estados de Baja California, Baja California Sur, Sinaloa y Sonora; región Norte: Coahuila, Chihuahua y Durango; región Noreste: Nuevo León y Tamaulipas; región Centro-Norte: Aguascalientes, Guanajuato, Querétaro, San Luís Potosí y Zacatecas; región Golfo: Tabasco y Veracruz; región Occidente: Colima, Jalisco, Michoacán y Nayarit; región Centro: Hidalgo, Morelos, Estado de México, Puebla, Tlaxcala y el Distrito Federal; región Pacífico: Chiapas, Guerrero y $\mathrm{Oa}$ xaca; región Península de Yucatán: Campeche, Quintana Roo y Yucatán. 


\section{GRÁFICA 1}

Empleo creado en la industria manufacturera por región y en el D.F. entre 1980 y 1993

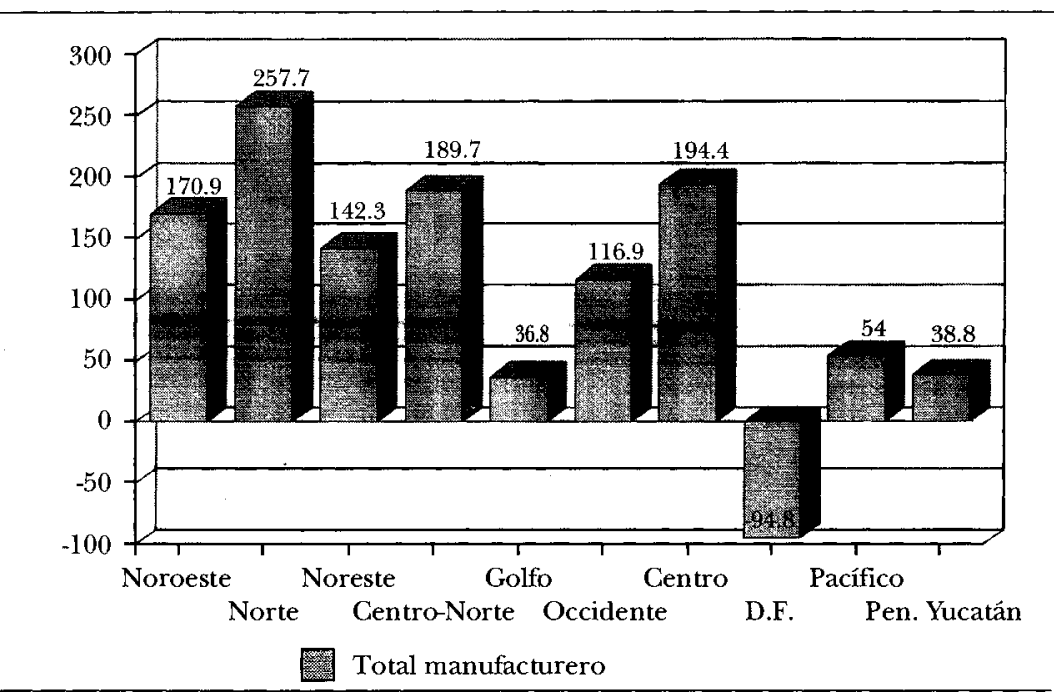

tro-Norte, con tasas de crecimiento de $8.1,7.6$ y 6.2 respectivamente, quejuntas aportaron $55.8 \%$ o 618424 empleos creados (gráfica 1). El menor dinamismo, tal como lo indicaban ya los datos por estado, lo tuvieron las regiones Centro (0.7), Golfo (2.7), Occidente (3.7) y Noreste (3.6), aunque su aporte en conjunto también se mantuvo elevado (44.4\% o 490558$)$. Al distinguir entre ramas exportadoras y no exportadoras, en las tres regiones del norte del país y el Centro-Norte se concentraba $83.4 \%$ del empleo generado en las ramas exportadoras, aunque es notoria la mayor importancia de la región Norte. El mayor incremento en las no exportadoras se dio en el Centro, Occidente y Centro-Norte (cuadro 2b y gráfica 2).

Es precisamente en la región Norte donde se concentra $66 \%$ de los nuevos empleos en las ramas exportadoras líderes (gráfica 3), y junto con la Noroeste y Noreste, $99 \%$. En este caso la región Centro perdió 17.8 puntos y Golfo 0.6. De las ramas exportadoras tradicionales (gráfica 4), aunque las regiones Norte y Centro-Norte tienen la más alta participación en conjunto, fue en la región Centro donde se crearon más empleos. Otras ramas exportadoras (gráfica 5) están completamente 


\section{GRÁFICA 2}

Empleo creado en ramas exportadoras de la industria manufacturera por región y en el D.F. entre 1980 y 1993 (miles)

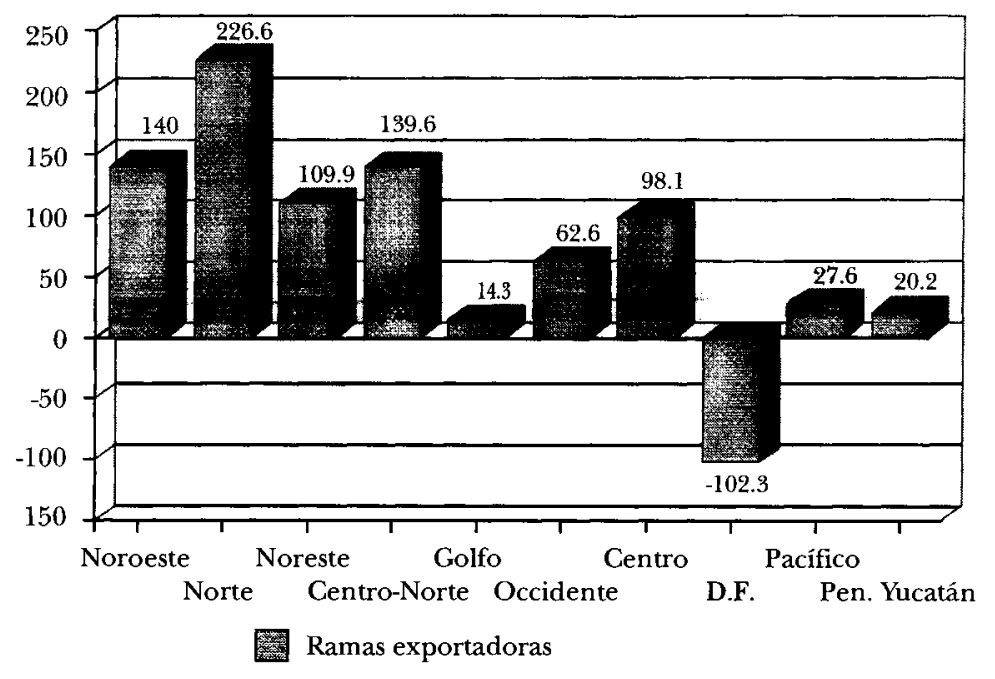

volcadas hacia el norte, mientras que el centro muestra desindustrialización. Finalmente, es en las ramas no exportadoras (gráfica 6) donde la región Centro hace su mayor aportación.

\section{Comportamiento del PIB}

Continuando con la distinción entre nuevos y viejos centros industriales -excluido el Distrito Federal-, ${ }^{13}$ los hallazgos realizados a partir del cuadro 3a resultan bastante interesantes, ya que aun cuando los nuevos centros alcanzaran tasas de crecimiento superiores al promedio nacional y al conjunto de centros tradicionales, fueron estos últimos los que aportaron $47 \%$ del PIB manufacturero en el periodo analizado, contra $24.3 \%$ de los primeros.

${ }^{13}$ A diferencia del empleo, el Distrito Federal tuvo un desempeño positivo en la generación de valor agregado, y aun cuando fue producto de una baja tasa de crecimiento, representó $6.7 \%$ del incremento nacional entre 1980 y 1993. 


\section{GRÁFICA 3}

Empleo creado en ramas manufactureras exportadoras líderes por región y en el D.F. entre 1980 y 1993 (miles)

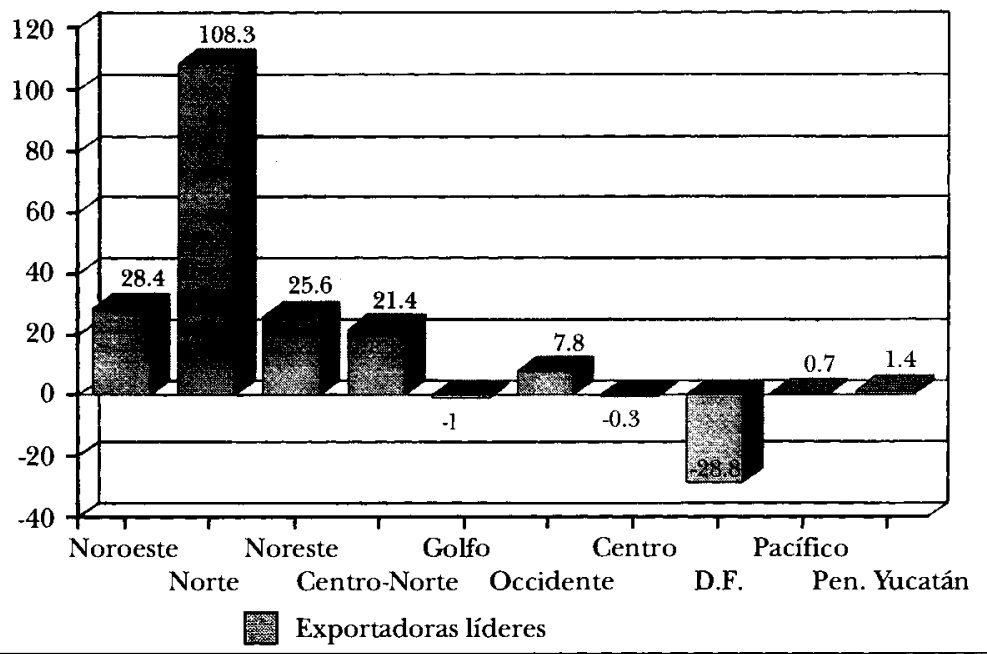

\section{GRÁFICA 4}

Empleo creado en ramas manufactureras exportadoras tradicionales por región y en el D.F. entre 1980 y 1993 (miles)

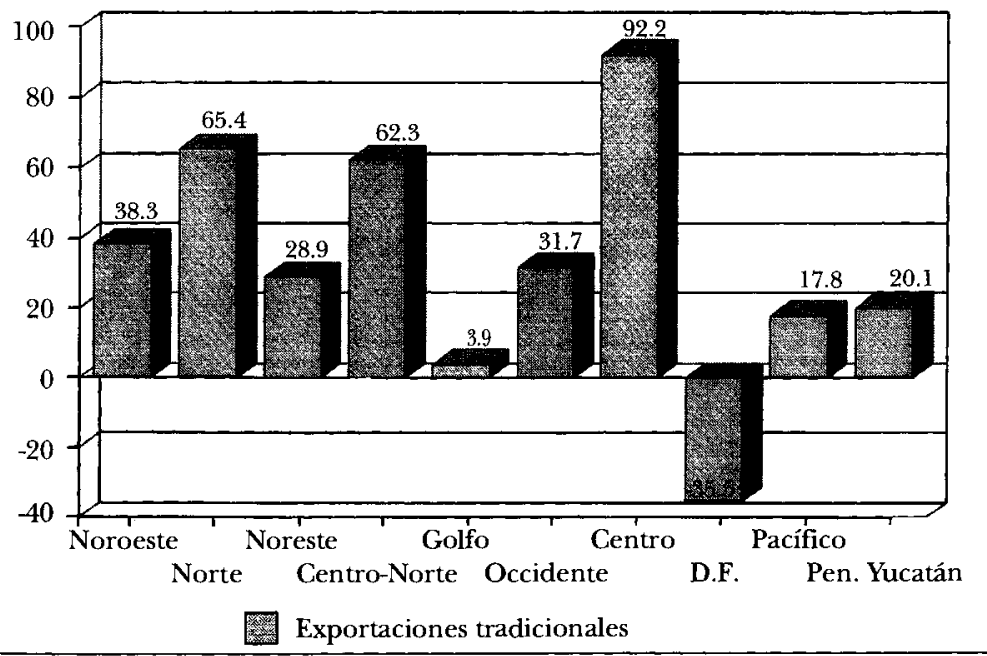


GRÁFICA 5

Empleo creado en "otras" ramas manufactureras exportadoras por región y en el D.F. entre 1980 y 1993 (miles)

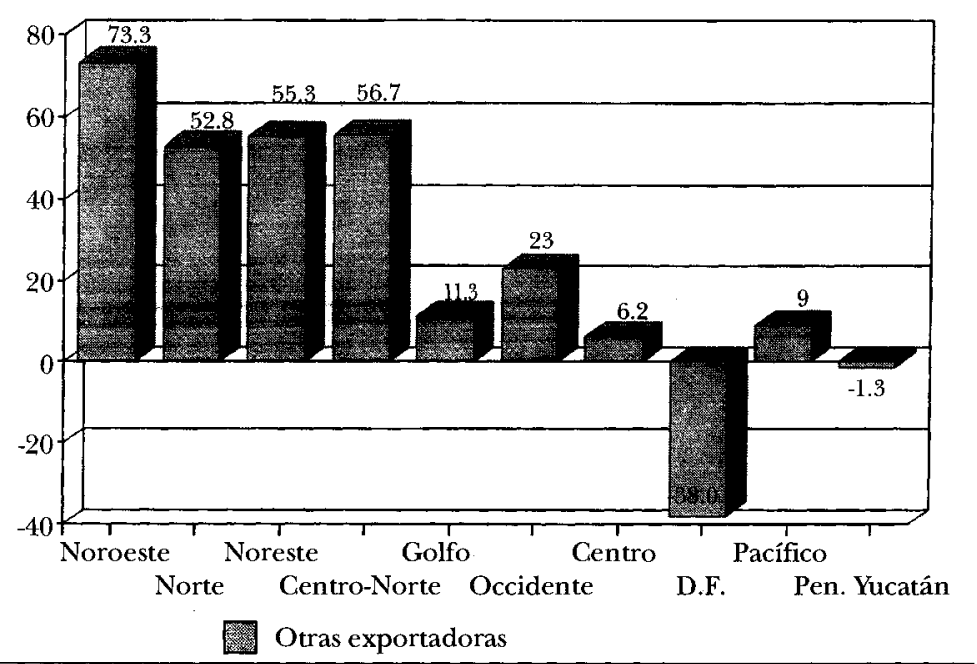

GRÁFICA 6

Empleo creado en ramas no exportadoras de la industria manufacturera por región y en el D.F. entre 1980 y 1993 (miles)

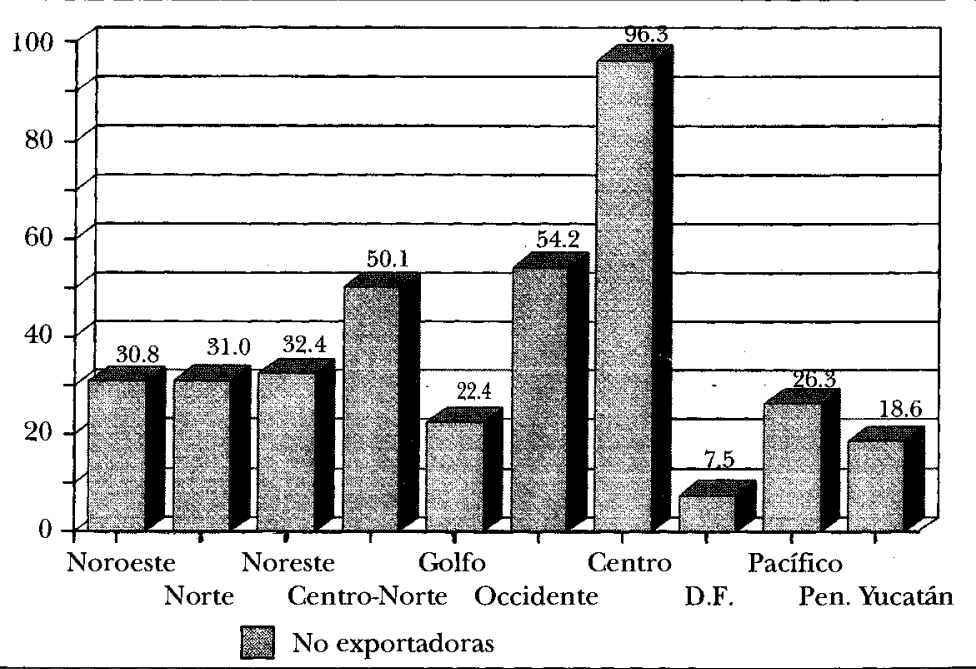


En las ramas exportadoras los viejos centros industriales aportaron $45.5 \%$ del PIB generado, por $36.7 \%$ de los nuevos centros. En las no exportadoras la relación fue de 49.1 y $10.5 \%$. En las ramas exportadoras tradicionales y "otras" exportadoras la situación fue parecida. Sólo en las ramas exportadoras líderes la relación fue opuesta: los viejos centros aportaron $3.5 \%$ y los nuevos 62.8 por ciento.

Dentro de las regiones hay variaciones importantes en relación con lo que le sucede al empleo. Llama la atención la fuerte presencia que mantiene la región Centro (cuadro 3b), donde se creó la mayor parte del PIB total manufacturero (19.6\%). Igual ocurre con las ramas exportadoras $(20.2 \%)$, las tradicionales $(26.6 \%)$ y las no exportadoras (18.8\%). En las ramas líderes el mayor aporte lo hacen las regiones Noroeste $(15.4 \%)$, Norte $(38.5 \%)$ y Centro-Norte $(19.6 \%)$, aunque es importante la contribución de la Centro (14.9\%) y la Occidente (12.2\%). Finalmente en "otras exportadoras" aunque las regiones del norte concentran la aportación del PIB, las del Golfo, Occidente y Centro hacen un aporte muy importante (véase las gráficas 7 a 12).

Una síntesis de la distribución sectorial y regional del auge exportador manufacturero podría ser la siguiente:

1) Las ramas exportadoras líderes tienen alto peso en las exportaciones pero muy bajo en la generación de empleo y mediano en el PIB.

2) La mayor contribución en la generación de empleo manufacturero, por lo tanto, corresponde a las ramas exportadoras tradicionales, otras exportadoras y no exportadoras.

3) La mayor parte del PIB es creada en las ramas no exportadoras, seguidas por las exportadoras tradicionales; las ramas líderes se ubican en tercer lugar, con una participación muy parecida a la de "otras exportadoras".

4) El empleo creado en los sectores líderes y "otros exportadores" es el de mayor concentración territorial en el país, siendo su ubicación preferida el norte y centro norte; el de los sectores exportadores tradicionales se reparte entre los nuevos y viejos centros tradicionales con un predominio del centro; y el de las ramas no exportadoras es el que tiene una distribución más homogénea, pero también con un predominio del centro.

5) El centro y el Distrito Federal son los mayores generadores del PIB manufacturero, sin embargo el de las ramas exportadoras líderes se reparte entre los viejos y los nuevos centros industriales, con predominio de la región Norte. La distribución es igual en las exportadoras tradicionales, pero esta vez con un predominio del centro. 


\section{GRÁFICA 7}

PIB generado en industria manufacturera por región y en el D.F. entre 1980 y 1993 (miles de millones de pesos de 1980)

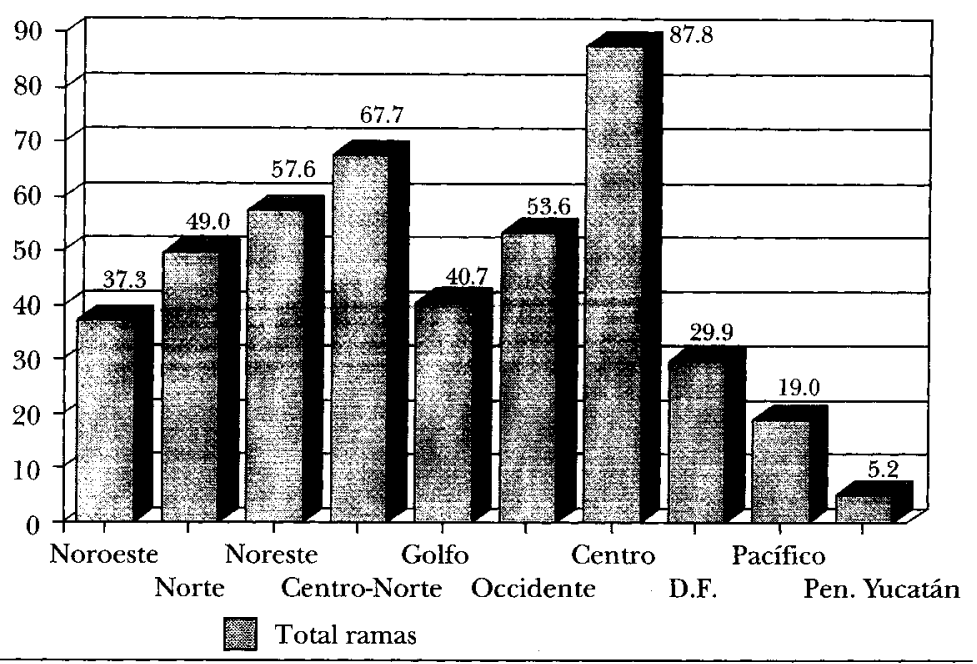

\section{GRÁFICA 8}

PIB generado en ramas exportadoras de la industria manufacturera por región y en el D.F. entre 1980 y 1993 (miles de millones de pesos de 1980)

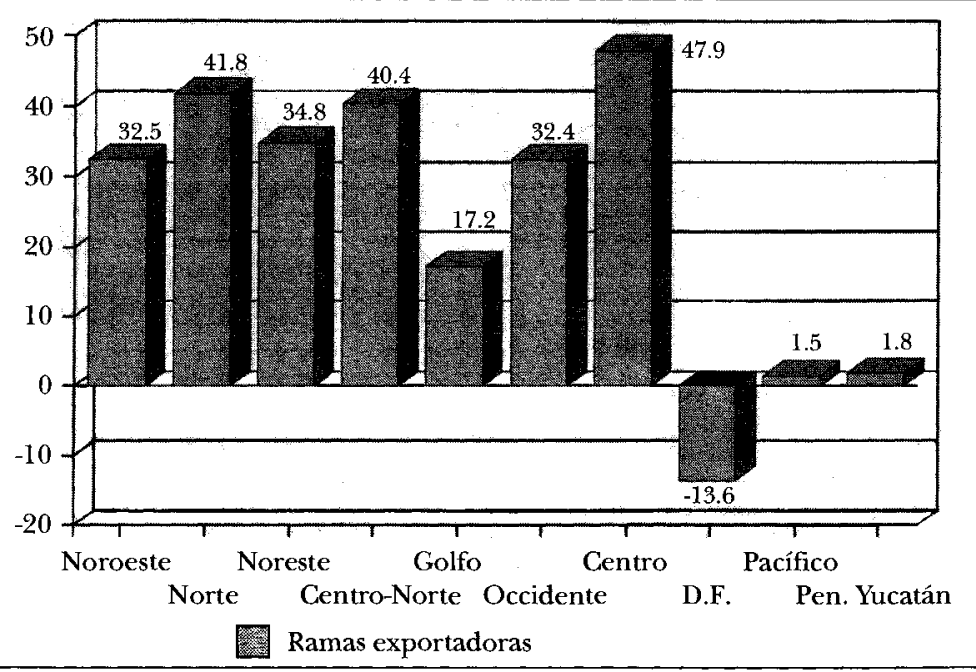


GRÁFICA 9

PIB generado en las ramas manufactureras exportadoras líderes por región y en el D.F. entre 1980 y 1993 (miles de millones de pesos de 1980)

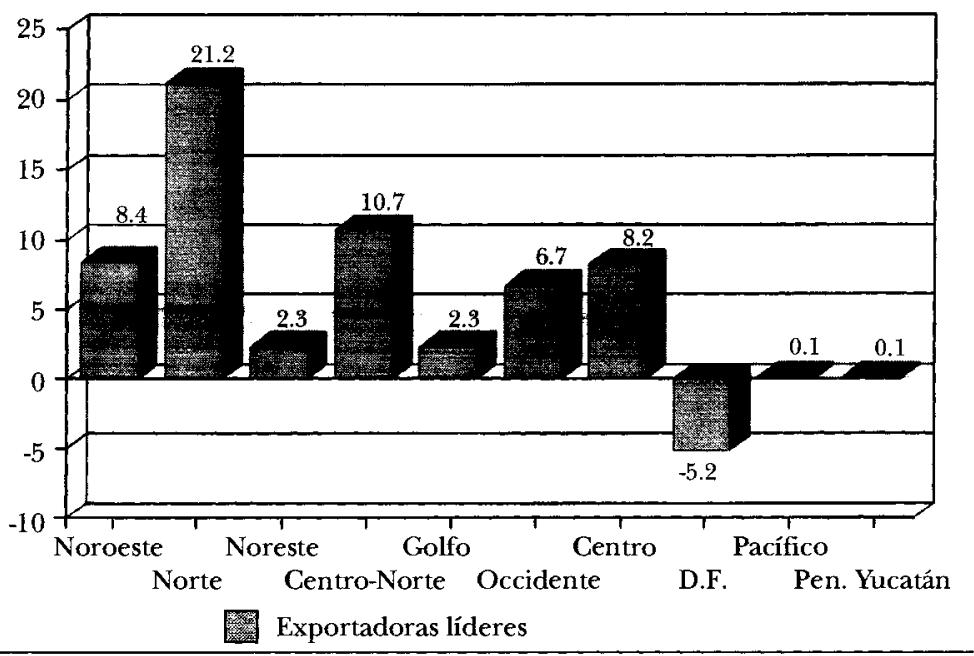

\section{GRÁFICA 10}

PIB generado en ramas manufactureras exportadoras tradicionales por región y en el D.F. entre 1980 y 1993 (miles de millones de pesos de 1980))

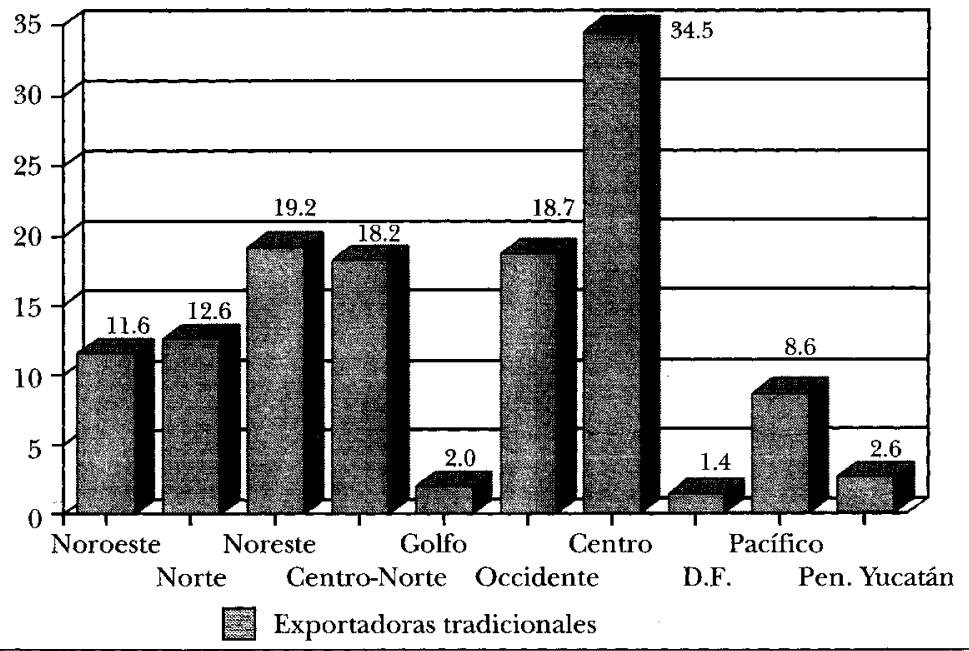




\section{GRÁFICA 11}

PIB generado en "otras" ramas manufactureras exportadoras por región y en el D.F. entre 1980 y 1993 (miles de millones de pesos de 1980)

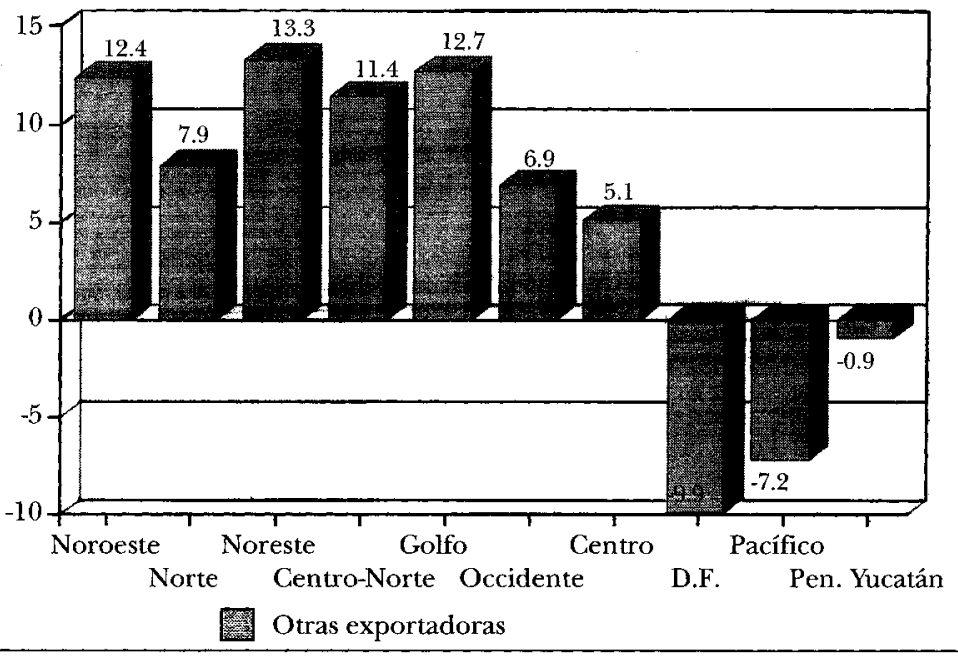

\section{GRÁFICA 12}

PIB generado en ramas no exportadoras de la industria manufacturera por región y en el D.F. entre 1980 y 1993 (miles de millones de pesos de 1980)

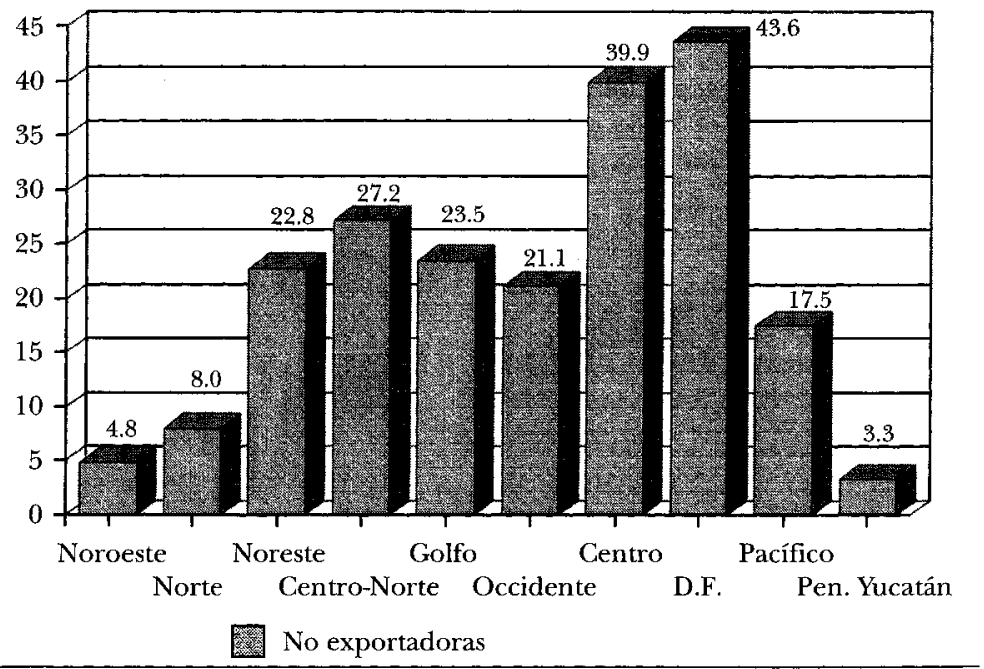


6) En el caso de "otras exportadoras", participan igual las dos franjas geográficas, mientras que en las no exportadoras comparten su participación las antiguas regiones industriales y las del sur.

7) Por lo anterior, se puede hablar de un proceso de desindustrialización relativa en la región Centro (según empleo), y otro más de desindustrialización absoluta en la ciudad capital.

En suma, el crecimiento de las industrias de alta tecnología aceleró el desarrollo desigual, por una diferenciación intersectorial de la economía, y profundizó la reorganización espacial de la producción. Estos cambios territoriales son resultado de la reestructuración económica en general y de la industrial en particular, que ha vivido el país desde mediados de los años ochenta, así como de la crisis económica de esa década y los programas de ajuste que se instrumentaron para enfrentarla. El factor externo ha tenido un gran peso en la evolución de la nueva localización industrial, dado que las corrientes de inversión han optado por los espacios emergentes de la frontera norte del país, así como por las grandes metrópolis tradicionales. En este sentido, la pérdida de participación relativa de la Zona Metropolitana de la Ciudad de México y demás megaciudades en términos económicos y demográficos durante los años ochenta, fue solo temporal. Los datos de 1993 sugieren que efectivamente se ha conformado un patrón de concentración industrial policéntrico, y que las posteriores etapas de recesión y crecimiento no provocarán los mismos efectos adversos que ocasionaron sobre las entidades de antigua industrialización.

Ahora bien, la distribución espacial de la industria es importante no sólo por la reconfiguración urbana y regional a que está asociada, sino también porque está muy relacionada con las opciones de política que deben impulsarse, si se considera que cada espacio o región procesa de manera diferente sus respuestas a los cambios mundiales en función de sus especificidades (Alba et al., 1998)y porque sólo con carácter subnacional es posible impulsar acciones concretas para remover los obstáculos al crecimiento.

Es fundamental considerar, sin embargo, que gran parte de los nuevos esquemas de apoyo y actuación tendrá que surgir de los mismos espacios económicos involucrados, y que no se trata tan sólo de un desafio económico sino también de uno social. 
Implicaciones económicas y de política industrial de la nueva geografía industrial

La distribución de la industria manufacturera en el territorio y por tipo de ramas exportadoras y no exportadoras, muestra su reacomodo en dos grandes franjas del país y además permite proponer argumentos para un replanteamiento de los objetivos y estrategias de política industrial. Para tal propósito resulta útil preguntarse sobre los beneficios y costos que ha acarreado el dinamismo de las exportaciones de las divisiones ganadoras y el de las perdedoras; asimismo parece conveniente explorar las condiciones que afectan su desempeño económico en los distintos ámbitos territoriales.

Las ganancias y pérdidas se entienden básicamente en términos de la difusión de beneficios que se dan o dejan de dar al resto de la economía por efecto del crecimiento de uno u otro tipo de industria, y por el grado de autonomía del que se dispone para ejercer capacidades decisorias. No menos importantes, aunque no exclusivos de un grupo, son los avances o retrocesos en productividad y competitividad.

Sobre la competitividad se sabe que varía en función de factores que pueden afectar al salario, a la capacidad organizativa y tecnológica de las empresas, o a las políticas monetarias y comerciales. Los dos primeros inciden directamente sobre la productividad, ya sea del trabajo o del total de los factores, siendo considerada la primera de ellas poco benéfica en términos sociales. Según la opinión de varios autores aquí citados, en la mayoría de las ramas cuya competitividad mejoró en el periodo considerado, el factor determinante fue la mayor productividad del trabajo; en las ramas rezagadas, mientras tanto, la competitividad estuvo más asociada a los bajos salarios (Casar, 1993). Unger (1993) sostiene que con pocas excepciones, los sectores logran aumentos de productividad más por la reducción de la fuerza laboral que por otros factores.

Ahora bien, sobre los beneficios para el conjunto de la economía, aun cuando las exportaciones de manufacturas ligeras (las perdedoras) dependen de insumos del exterior, éstos son poco relevantes para la balanza comercial mexicana; por el contrario, el hecho de que esté mejor distribuida territorialmente su producción y tenga efectos multiplicadores de arrastre difunde el desarrollo al resto de la economía nacional. Son asimismo ramas en que se han especializado muchas regiones, donde es importante la presencia de capital nacio- 
nal y por consiguiente se tiene la capacidad de decidir sobre las estrategias productivas y las políticas comerciales.

Las ramas ganadoras por su parte, al ser resultado de la vinculación intrasectorial entre México y Estados Unidos, con alta demanda de bienes intermedios, afectan negativamente la balanza comercial del país. Si bien están comprendidos los bienes de capital y tienen importantes efectos de arrastre hacia atrás en el caso de los bienes intermedios, se trata de ramas controladas por empresas trasnacionales que solo dinamizan fuertemente el mercado estadunidense. Más aún, el importante volumen de transacciones que implican se da únicamente dentro de un sector (como el automotriz, el químico), pero fuera de la estructura productiva nacional.

Con pocas excepciones, las exportaciones mexicanas hacia Estados Unidos se caracterizan por su nula participación como insumos en la producción, en tanto que las exportaciones estadunidenses a México sí generan efectos hacia adelante. No obstante, son las exportaciones tradicionales las que más benefician la estructura industrial mexicana en cuanto a valor de la producción, empleo y efectos de arrastre (véase Martínez, 1994).

Cabe mencionar en descargo de la industria exportadora del norte del país que representa beneficios en términos de las mejoras organizacionales de las empresas, en la difusión de avances tecnológicos, y en la absorción de empleos.

Las implicaciones de política son claras, y consisten en determinar cómo articular a los sectores manufacturero tradicional y moderno de México mediante el fortalecimiento de las cadenas productivas, y cómo territorializar la producción, es decir, cómo fortalecer la capacidad de mantener el control estratégico de la planta productiva y difundir sus beneficios a donde sea necesario, sin que ello signifique aislarse de las tendencias mundiales. En este caso las ramas tradicionales cuentan con varias ventajas: son ramas que se reestructuran; que conservan en parte el mercado nacional; que participan -algunas de ellas- en forma importante en el mercado internacional; que en los casos en que no han fortalecido las cadenas productivas internas estarian en posibilidad de hacerlo; y que conservan el espíritu colectivo en las negociaciones laborales, aún cuando las relaciones hayan variado ostensiblemente. ${ }^{14}$

${ }^{14}$ Una diferencia importante entre la industrialización del norte y la del centro de México es que en el norte, por tratarse de un proceso relativamente reciente bajo una 
Los riesgos están claro: a nivel macro, la creciente vulnerabilidad del país por la poca diversificación real de sus opciones comerciales; a nivel regional, por la dependencia de una sola industria o actividad: en estados como Aguascalientes, Coahuila, Chihuahua, Puebla y Sonora, por ejemplo, el peso del sector automotriz es cada vez mayor, en cada uno de ellos representa respectivamente, 59.7, 62.3, 56.4, 79.9 y $79.7 \%$ del valor de la producción.

Para finalizar, es indispensable considerar dos aspectos en cualquier propuesta de apoyo a la actividad industrial, aunque también son válidos para los demás sectores:

1) "Los países que aparecen como los más eficientes, son aquellos cuyos grupos de actores han logrado organizar procesos de aprendizaje y de decisión rápidos y efectivos, y han podido plasmar las nuevas exigencias en el ámbito empresarial" (Messner, 1996: 14).

2) La política industrial constituye solamente una escala (macro) de atención a los problemas económicos, quedan los niveles meso y micro, que es donde realmente se construye la competitividad con base en la movilización de recursos monetarios y productivos a partir de acuerdos sociales entre los distintos gobiernos y grupos de actores.

La territorialización de las políticas es un medio práctico y operacional para contribuir al balance entre crecimiento económico y estabilidad social.

\section{Bibliografía}

Alba, Carlos et al. (comps.) (1998), Las regiones ante la globalización, México, CEMCA/ORSTOM/EI Colegio de México.

Bielschowsky, R. y G. Stumpo (1995), "Empresas transnacionales en las industrias de Argentina, Brasil, Chile y México", Revista de la CEPAL, núm. 55, pp. 139-164.

Banco Interamericano de Desarrollo (1992), 'Progreso económico y social en 'América Latina. Informe 1992, Washington.

lógica de despegue y con fuerte presencia de capital extranjero, la organización industrial muy probablemente profundizará en los aspectos de flexibilidad laboral sin la participación colectiva de los trabajadores, y en la falta de encadenamientos locales. En la región central, mientras tanto, con una trayectoria de más larga duración, se da una recomposición de las actividades en donde los grupos oligopólicos nacionales aún mantienen el control de las decisiones más importantes, lo cual podría favorecer el desarrollo regional. 
Bustelo, Pablo (1992), "La industrialización en América Latina y Asia oriental: un análisis comparado", Comercio Exterior, vol. 42, núm. 12, pp. 1111-1119.

Cappecchi, V. (1989), "The Informal Economy and the Development of Flexible Specialization in Emilia-Romagna", en Portes et al. (eds.), The Informal Economy. Studies in Advanced and Less Devloped Countries, The Johns Hopkins University Press, pp. 189-215.

Ciccolella, P. (1999), "Globalización y dualización en la Región Metropolitana de Buenos Aires. Grandes inversiones y reestructuración socioterritorial en los años noventa", 'EURE. Revista Latinoamericana de Estudios Urbano Regionales, vol. 25, núm. 76, pp. 1-23.

Casar, Jorge (1993), "La competitividad de la industria manufacturera mexicana, 1980-1990, El Trimestre Económico", vol. 60, núm. 1, pp. 113-184.

Conde, Raúl (1996), "Políticas de comercio exterior: evaluación y alternativas", en Enrique de la Garza (coord.), Politicas públicas altemativas en México, La Jornada Ediciones/UNAM, pp. 141-169.

Dabat, Alejandro y Miguel Ángel Rivera (1994), "Las transformaciones de la economía mundial", en Alejandro Dabat (coord.), México en la econoriía global, Guernavaca, UNAM, pp. 15-38.

De la Garza, E. (1993), Reestructuración productiva y respuesta sindical en México, Instituto de Investigaciones Económicas, México, UNAM/UAM-I.

Dematteis, G. (1986), "Urbanization and Counter-Urbanization in Italy", Ekistics, vol. 53, núm. 2, pp. 316-317.

Dicken, Peter (1992), Global Shift. The Intermationalization of Economic Activity, Nueva York, The Guilford Press.

Dunford, M. y D. Perrons (1986), "The Restructuring of the Post-War British Space Economy", en R. Martin y B. Rowthorn (eds.), The Geography of DeIndustrialization, Hong Kong, MacMillan Education.

Dussel, E. (1995), "El cambio estructural del sector manufacturero mexicano, 1988-1994", Comercio Exterior, vol. 45, núm. 6, pp. 460 a 469.

Frey, W. (1989), "United States: Counterurbanization and Metropolis Depopulation", en A. Champion (ed.), Counterurbanization. The Changing Pace and the Nature of Population Deconcentration, Londres, Arnold.

- y A. Speare (1992), "The Revival of Metropolitan Population Growth in the United States: an Assesment of Findings from the 1990 Census", Population and Development Review, vol. 18, núm. 1.

Garza, Gustavo (1998), "Globalización económica, concentración metropolitana y políticas urbanas en México”, Estudios Demográficos y Urbanos, vol. 13, núm. 2, pp. 269-311.

Glickman, N. (1987), "Cities and the International Division of Labor", en P. Smith y J. Feagin (eds.), The Capitalist City. Global Restructuring and Community Politics, Basil Blackwell, pp. 66-86.

Guadarrama, Julio (1995), "El desarrollo urbano y metropolitano ante la reestructuración económica del capitalismo, 1970-1990", México (mimeo.). 
Kontuly, T. (1992), "National, Regional, and Urban-Scale Population Deconcentration in West Germany", Landscape and Planning, vol. 22, núm. 2-4.

Lipietz, A. y D. Leborgne (1990), "Nuevas tecnologías, nuevas formas de regulación. Algunas consecuencias espaciales", en F. Alburquerque et al. (eds.), Revolución tecnológica y reestructuración productiva: Impactos y desafios territoriales, Buenos Aires, Grupo Editor Latinoamericano, pp. 103-136.

Loria, Jorge (1997), "Boom exportador, crecimiento y bienestar", La Jormada, 1 de junio, p. 22.

- (1999), "Efectos de la apertura comercial en la manufactura mexicana, 1980-1998", Investigación Económica, vol. 59, núm. 230, pp. 55-82.

Martínez Morales, Gerardo (1994), "Libre comercio, maquiladoras y desarrollo regional. La industria maquiladora en la región Noreste ante el TLC", en Héctor Dávila (coord.), TLC: Impactos en la frontera norte, México, Facultad de Economía, UNAM, pp. 53-69 (Libros de Investigación Económica).

Massey, D. (1986), "The Legacy Lingers on: The Impact of Britain's International Role on its Internal Geography", en R. Martin y B. Rowthorn (eds.), The Geography of De:Industrialization, Hong Kong, MacMillan Education.

Mattos, C. de (1999), "Santiago de Chile, globalización y expansión metropolitana: lo que existía sigue existiendo", EURE. Revista Latinoamericana de Estudios Urbano Regionales, vol. 25, núm. 76, pp. 1-28.

Messner, Dirk (1996), "Dimensiones espaciales de la competitividad internacional", Revista Latinoamericana de Estudios del Trabajo, año 2, núm. 3, pp. $15-40$.

Olivera, Guillermo (1997a), "La pequeña industria en el proceso de reestructuración industrial y desconcentración territorial en el mundo y en México", Investigación Económica, vol. 57, núm. 220, pp. 67-95.

- (1997b), "Transformación metropolitana en México: Efectos económico-territoriales del comercio exterior", Comercio Exterior, vol, 47, núm. 4, pp. 259-269.

ONUDI (Organización de las Naciones Unidas para el Desarrollo Industrial) (1997), Desarrollo industrial. Informe mundial 1996, México, FCE.

Pólese, Mario y Salvador Pérez (1995), "Integración económica norteamericana y cambio regional en México", Comercio Exterior, vol. 45, núm. 2, pp. 132-139.

Ros, Jaime (1997), "La enfermedad mexicana", Nexos, núm. 235, pp. 57-59.

Rueda, Isabel (1995), "La industria manufacturera mexicana y la crisis actual", Problemas del Desarrollo, vol. 26, núm. 101, pp. 145-172.

Savey, S. (1983), "Organization of Production and the New Spatial Division of Labor in France", en F. Hamilton y G. Linge (eds.), Spatial Analysis, Industry and the Industrial Environment, vol. Ill, Regional Economies and Industrial Environment, Irlanda del Norte, John Willey \& Sons.

Smith, P. y J. Feagin (1987), "Cities and the New International Division of Labour: An Overview", en P. Smith y J. Feagin (eds.), The Capitalist City. Global Restructuring and Community Politics, Basil Blackwell, pp. 8-26. 
Storper Michael (1993), The Global Economy and Territoriality of Economic Development: Notes on a Research Agenda for the 1990s, Los Ángeles, Graduate School of Architecture and Urban Planning, University of California.

Trejo, Saúl (1987), El futuro de la política industrial en México, México, El Colegio de México.

Unger, Kurt (1993), "Productividad, desarrollo tecnológico y competitividad exportadora en la industria mexicana”, Economía Mexicana, Nueva Época, vol. 2, núm. 1, pp. 183-237.

Vázquez, Héctor (1995), "Medición y flujo efectivo de divisas de la balanza comercial”, Comercio Exterior, vol. 45, núm. 8, pp. 595-600.

Vera, Alejandro (1996), "La inversión extranjera y el desarrollo competitivo en América Latina y el Caribe”, Revista de la CEPAL, núm. 60, pp. 129-149. Vidal, G. (2000), "Comercio exterior, inversión extranjera y grandes empresas en México", Comercio Exterior, vol. 50, núm. 7, pp. 587-595. 